\title{
Stress Regulates Aquaporin-8 Permeability to Impact Cell Growth and Survival
}

\author{
Iria Medraño-Fernandez,, ${ }^{1, \star}$ Stefano Bestetti,, ${ }^{1, *}$ Milena Bertolotti, ${ }^{1}$ Gerd P. Bienert, ${ }^{2}$ Cinzia Bottino, \\ Umberto Laforenza, ${ }^{3}$ Anna Rubartelli, and Roberto Sitia ${ }^{1}$
}

\begin{abstract}
Aquaporin-8 (AQP8) allows the bidirectional transport of water and hydrogen peroxide across biological membranes. Depending on its concentration, $\mathrm{H}_{2} \mathrm{O}_{2}$ exerts opposite roles, amplifying growth factor signaling in physiological conditions, but causing severe cell damage when in excess. Thus, $\mathrm{H}_{2} \mathrm{O}_{2}$ permeability is likely to be tightly controlled in living cells. Aims: In this study, we investigated whether and how the transport of $\mathrm{H}_{2} \mathrm{O}_{2}$ through plasma membrane AQP8 is regulated, particularly during cell stress. Results: We show that diverse cellular stress conditions, including heat, hypoxia, and ER stress, reversibly inhibit the permeability of AQP8 to $\mathrm{H}_{2} \mathrm{O}_{2}$ and water. Preventing the accumulation of intracellular reactive oxygen species (ROS) during stress counteracts AQP8 blockade. Once inhibition is established, AQP8-dependent transport can be rescued by reducing agents. Neither $\mathrm{H}_{2} \mathrm{O}_{2}$ nor water transport is impaired in stressed cells expressing a mutant AQP8, in which cysteine 53 had been replaced by serine. Cells expressing this mutant are more resistant to stress-, drug-, and radiation-induced growth arrest and death. Innovation and Conclusion: The control of AQP8-mediated $\mathrm{H}_{2} \mathrm{O}_{2}$ transport provides a novel mechanism to regulate cell signaling and survival during stress. Antioxid. Redox Signal. 24, 1031-1044.
\end{abstract}

\section{Introduction}

$\mathbf{T}$ He pathophysiology of $\mathrm{H}_{2} \mathrm{O}_{2}$ exemplifies how reactive oxygen species (ROS) are double-edged swords in the cell signaling armamentarium: $\mathrm{H}_{2} \mathrm{O}_{2}$ is toxic at high concentrations, but at the same time, it is an essential second messenger in charge of modulating diverse signaling pathways $(12,15,17,36)$. Among these, $\mathrm{H}_{2} \mathrm{O}_{2}$ inactivates tyrosine phosphatases by oxidizing essential cysteines in their active sites and activates certain kinases, including members of the mitogen-activated kinase family (MAPKs). The sum of these activities results in the amplification of tyrosine phosphorylation cascades $(35,38)$. Therefore, the mechanisms that control $\mathrm{H}_{2} \mathrm{O}_{2}$ production, transport, diffusion, and clearance in human cells are of paramount biomedical interest (21).
Owing to their membrane topology, NADPH oxidases (NOXes) generate superoxide in the external leaflet of the plasma membrane or in the lumen of endocytic and exocytic organelles (4). Dismutases rapidly convert superoxide into

Innovation
Our study reveals a novel layer of control in the redox
signaling circuitry that impacts cell resistance to stress and
survival. The key finding is that living cells can regulate
the permeability of aquaporin- 8 to $\mathrm{H}_{2} \mathrm{O}_{2}$ and $\mathrm{H}_{2} \mathrm{O}$, par-
ticularly during stress. The mechanism we disclose in-
fluences cell life-death decisions and can lead to the
identification of drug targets with wide implications in
tumor biology and other stress-related pathological con-
ditions.

\footnotetext{
${ }^{1}$ Protein Transport and Secretion Unit, Division of Genetics and Cell Biology, IRCCS Ospedale San Raffaele/Università Vita-Salute San Raffaele, Milan, Italy.

${ }^{2}$ Metalloid Transport Group, Leibniz Institute of Plant Genetics and Crop Plant Research, Gatersleben, Germany.

${ }^{3}$ Department of Molecular Medicine, University of Pavia, Pavia, Italy.

${ }^{4}$ Cell Biology Unit, IRCCS AOU San Martino-IST, Genoa, Italy.

*These authors contributed equally to this work.
} 
$\mathrm{H}_{2} \mathrm{O}_{2}$ that must then cross a lipid bilayer to reach its cytosolic targets. Recently, members of the aquaporin protein family (AQP), initially described as bidirectional water transporters (1), have been found to channel also $\mathrm{H}_{2} \mathrm{O}_{2}$ (7). We have recently shown that aquaporin-8 (AQP8) is essential to allow effective transport of $\mathrm{H}_{2} \mathrm{O}_{2}$ across the plasma membrane, thus potentiating tyrosine phosphorylation induced by growth factors (6), a notion later corroborated by others (57). These data confirmed that $\mathrm{H}_{2} \mathrm{O}_{2}$ acts as a rheostat of tyrosine kinase signaling and demonstrated that AQP8 guarantees efficient cytosolic import of $\mathrm{H}_{2} \mathrm{O}_{2}$ likely produced by NOXes. AQP8 silencing inhibited, in part, the transport of $\mathrm{H}_{2} \mathrm{O}_{2}$ through the ER membrane, but had little if any effect on mitochondria (6), where a fraction of AQP8 has been reported to localize (9). In other cell types, AQP3 $(18,39)$ and possibly different channels can allow efficient $\mathrm{H}_{2} \mathrm{O}_{2}$ transport.

Considering its importance in modulating growth factor downstream pathways, we surmised that AQP8-dependent $\mathrm{H}_{2} \mathrm{O}_{2}$ transport could be fine-tuned during stress conditions known to entail the production of $\operatorname{ROS}(51,52)$. Accordingly, we found that diverse cellular stresses reversibly inhibit AQP8-dependent transport, impacting cell growth and survival. The expression of an AQP8 mutant that does not undergo this inhibition increases the resistance of cells to heat-, arsenic trioxide-, and radiation-induced stress.

\section{Results}

Membrane permeability to $\mathrm{H}_{2} \mathrm{O}_{2}$ is impaired during cell stress

The hormetic properties of $\mathrm{H}_{2} \mathrm{O}_{2}$-essential for cell survival, but toxic at high concentrations-imply tight regulation of its intracellular levels. We reasoned that being more sensitive to oxidant toxicity $(11,42)$, cells undergoing stress might deploy mechanisms that limit $\mathrm{H}_{2} \mathrm{O}_{2}$ import. To test this possibility, we exposed human HeLa cells expressing an $\mathrm{H}_{2} \mathrm{O}_{2}$-specific ratiometric sensor in their cytosol [HyPerCyto (5)] to diverse chemical or physical stresses and followed the entry of exogenous $\mathrm{H}_{2} \mathrm{O}_{2}$ by live imaging. As shown in
Figure 1A, nonstressed cells (red line) display a characteristic shift in the ratio of HyPerCyto fluorescence emission (488/ $405 \mathrm{~nm}$ ) as exogenously added $\mathrm{H}_{2} \mathrm{O}_{2}$ enters the cytosol. The addition of extracellular catalase after $\mathrm{H}_{2} \mathrm{O}_{2}$ during our time course analyses rapidly eliminated this shift (Supplementary Fig. S1A; Supplementary Data are available online at www .liebertpub.com/ars). Thus, in control conditions, intracellular ROS produced in response to exposure to $\mathrm{H}_{2} \mathrm{O}_{2}$ plays a minor, if any, role in the activation of HyPerCyto, which detects mostly $\mathrm{H}_{2} \mathrm{O}_{2}$ imported through the plasma membrane. Having validated a system that allows us to register primarily the entry of exogenous molecules, we measured $\mathrm{H}_{2} \mathrm{O}_{2}$ permeability in stressed cells. Clearly, the activation of $\mathrm{Hy}$ perCyto was inhibited in cells exposed to different stressors, that is, the Hsp90 inhibitor, geldanamycin; the glycolytic inhibitor, 2-deoxyglucose; the ER stressor, tunicamycin; heat shock; and hypoxia (Fig. 1A). Similar results were obtained on different cells types, such as the murine B-lymphoma I. $29 \mu^{+}$or the human myeloma OPM2 (data not shown). In view of its efficacy and ease of control, we used heat shock for most experiments of stress induction.

\section{$\mathrm{H}_{2} \mathrm{O}_{2}$ transport inhibition is redox dependent}

The observation that different stressors inhibit $\mathrm{H}_{2} \mathrm{O}_{2}$ transport suggests the existence of mechanisms that reversibly gate its channel under stress conditions. As diverse stresses share the property of triggering ROS production by activating oxidases in target cells $(23,27,50)$, we hypothesized that the increase in the levels of ROS generated during stress was involved in the inhibition of exogenous $\mathrm{H}_{2} \mathrm{O}_{2}$ influx observed $(13,24,32,53)$. To verify this prediction, HeLa cells were exposed to heat stress in the presence of either diphenyleneiodonium (DPI), a compound that limits ROS production by inhibiting membrane-bound NOXes and other flavoproteins (31), or N-acetyl-cysteine (NAC), a widely used ROS scavenger. As shown in Figure 1B, addition of DPI or NAC during exposure to high temperature (gray bars) prevented stress-induced inhibition of $\mathrm{H}_{2} \mathrm{O}_{2}$ uptake. Similar results were obtained when cells were treated with tunicamycin
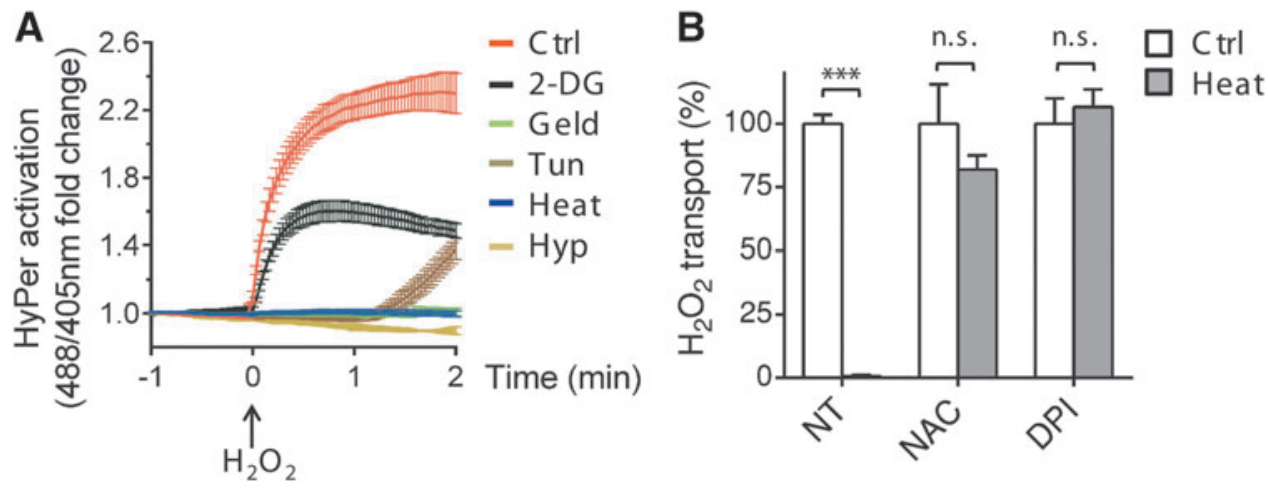

FIG. 1. Different stresses inhibit import of exogenous $\mathrm{H}_{2} \mathrm{O}_{2}$ in a redox-sensitive manner. (A) Kinetics of $H y P e r C y t o$ activation in stressed HeLa cells upon addition of exogenous $\mathrm{H}_{2} \mathrm{O}_{2}(50 \mu M)$ reveals an impairment of its transport through the plasma membrane. Data are shown as mean fold changes of the 488/405 nm ratio measured by confocal laser scanning, plotted against time \pm standard error of the mean (SEM). Ctrl, control conditions; 2-DG, 2-deoxyglucose; Geld, geldanamycin; Tun, tunicamycin; Heat, heat stress; Hyp, hypoxia. (B). Quantification of $\mathrm{H}_{2} \mathrm{O}_{2}$ uptake performed $90 \mathrm{~s}$ after addition of exogenous $\mathrm{H}_{2} \mathrm{O}_{2}$ to $\mathrm{HyPerCyto-HeLa}$ cells before or after heat stress, with or without either $10 \mu M$ DPI or $2 \mathrm{~m} M$ NAC. The data were normalized to the uptake of DPI- or NAC-treated unstressed cells. ${ }^{* * *} p<0.001$. Average of $\geq 3$ experiments \pm SEM. DPI, diphenyleneiodonium; NAC, N-acetyl-cysteine; n.s., non significant; NT, nontreated cells. To see this illustration in color, the reader is referred to the web version of this article at www.liebertpub.com/ars 
or cultured in hypoxic conditions in the presence of DPI (Supplementary Fig. S2). These observations suggested that elements of the transport mechanism are controlled by redoxmediated modification(s).

\section{AQP8 is the target of stress-dependent redox regulation}

Having shown before that human AQP8 is essential for efficient entry of $\mathrm{H}_{2} \mathrm{O}_{2}$ into living HeLa cells (6), we investigated whether this channel is the target of the regulatory modifications that hamper $\mathrm{H}_{2} \mathrm{O}_{2}$ uptake by stressed cells. To this end, cells silenced for AQP8 expression, and thus unable to import exogenous $\mathrm{H}_{2} \mathrm{O}_{2}$, were reconstituted with a vector driving the expression of a silencing-resistant Halo-tagged AQP8 (HaloAQP8) and stained using the Halo technology (40). Confirming our previous results (6), $\mathrm{H}_{2} \mathrm{O}_{2}$ transport was restored upon expression of the chimeric transgene (decorated in white in the pseudocolor scale used in Figure 2A and Supplementary Movie S1). Moreover, heat stress prevented $\mathrm{H}_{2} \mathrm{O}_{2}$ entry also in reconstituted cells (Fig. 2B, upper panels, and Fig. 2C, blue trace). Thus, HaloAQP8 transgene main- tains the properties of the endogenous channel proteins. Following our hypothesis, if the channel was controlled by redox-mediated modification(s), incubating heat-stressed cells with the reducing agent, dithiothreitol (DTT), immediately before exposure to exogenous $\mathrm{H}_{2} \mathrm{O}_{2}$ should recover transport only in cells expressing HaloAQP8. In fact, 5-min exposure to DTT partially rescued $\mathrm{H}_{2} \mathrm{O}_{2}$ entry only in the positive transfected cells (Fig. 2B, lower panels, Fig. 2C, orange trace, and see Supplementary Movie S2). The reducing agent caused an apparent small delay in $\mathrm{H}_{2} \mathrm{O}_{2}$ uptake when given to unstressed cells (Fig. 2B, black trace), which presumably reflects a potentiation of intracellular antioxidant systems and consequent rapid detoxification of the first internalized $\mathrm{H}_{2} \mathrm{O}_{2}$ molecules. Altogether, these observations further support the notion that AQP8 is a key target of the stress-induced redox regulatory modification(s).

\section{AQP8 cysteine mutants display different sensitivities to stress-induced transport inhibition}

The sensitivity to DTT and rapidity by which the reducing agent rescued transport suggested that upon stress, ROS-
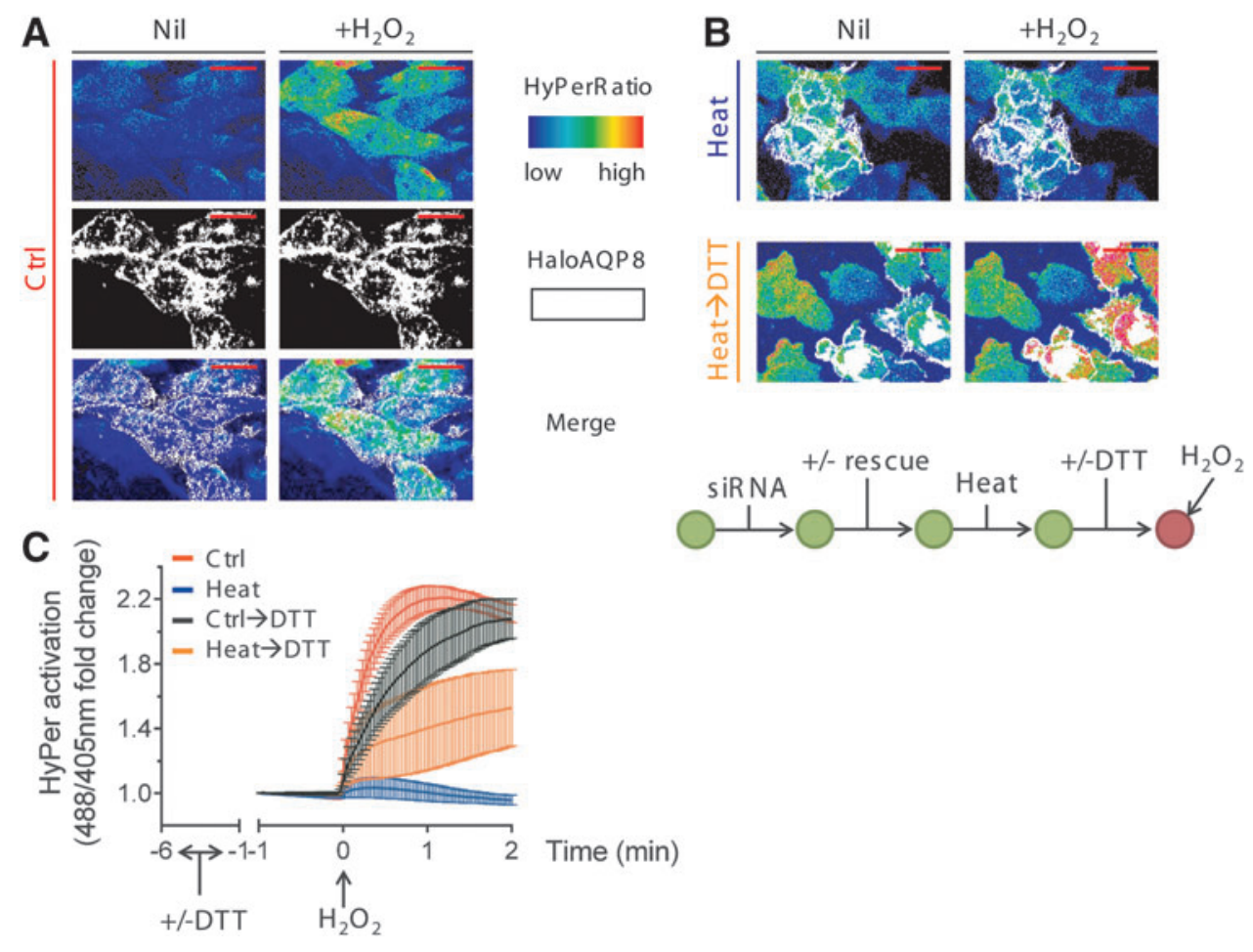

FIG. 2. AQP8 is the target of redox-dependent regulation of $\mathrm{H}_{2} \mathrm{O}_{2}$ permeability. (A) Frames extracted from a representative video of $\geq 3$ experiments, highlighting the kinetics of $\mathrm{H}_{2} \mathrm{O}_{2}$ import into silenced HeLa cells reconstituted with HaloAQP8 before (left panel) and after (right panel) addition of $50 \mu M$ exogenous $\mathrm{H}_{2} \mathrm{O}_{2}$. The 488/405 nm ratio is shown in pseudocolor (upper panel, the scale used is indicated in the insert). Cells positively transfected with HaloAQP8 wt are colored in white (middle panel). HyPerfluorescence ratio at baseline is variable from cell to cell, but the mean within a cell population is nearly the same in all experiments. The variability at the single-cell level explains why the basal colors presented in panels or figures sometimes differ. The scale bars correspond to $50 \mu \mathrm{m}$. Nil, nontreated cells. (B). The upper panels correspond to frames extracted from a video as in (A), showing no changes in the HyPerCyto ratios in HeLa cells reconstituted with HaloAQP8 under stress. The frames in lower panels show that recovery of $\mathrm{H}_{2} \mathrm{O}_{2}$ transport occurs only in cells expressing the transgene (colored in white) after a 5-min treatment with $5 \mathrm{~m} M$ DTT and two washes before the analysis. The experimental flow is depicted on the lower scheme for clarity. (C) Kinetics of $\mathrm{H}_{2} \mathrm{O}_{2}$ import into HeLa cells, in which AQP8 was silenced and then reconstituted with a silencing-resistant vector, driving the expression of HaloAQP8. Cells were heat shocked and then incubated with (orange trace) or without (blue trace) $5 \mathrm{~m} M$ DTT for $5 \mathrm{~min}$. Results represent the mean fold changes of the 488/405 nm ratio measured by confocal laser scanning, plotted against time. Average of $\geq 3$ experiments \pm SEM. AQP8, aquaporin- 8 . To see this illustration in color, the reader is referred to the web version of this article at www.liebertpub.com/ars 

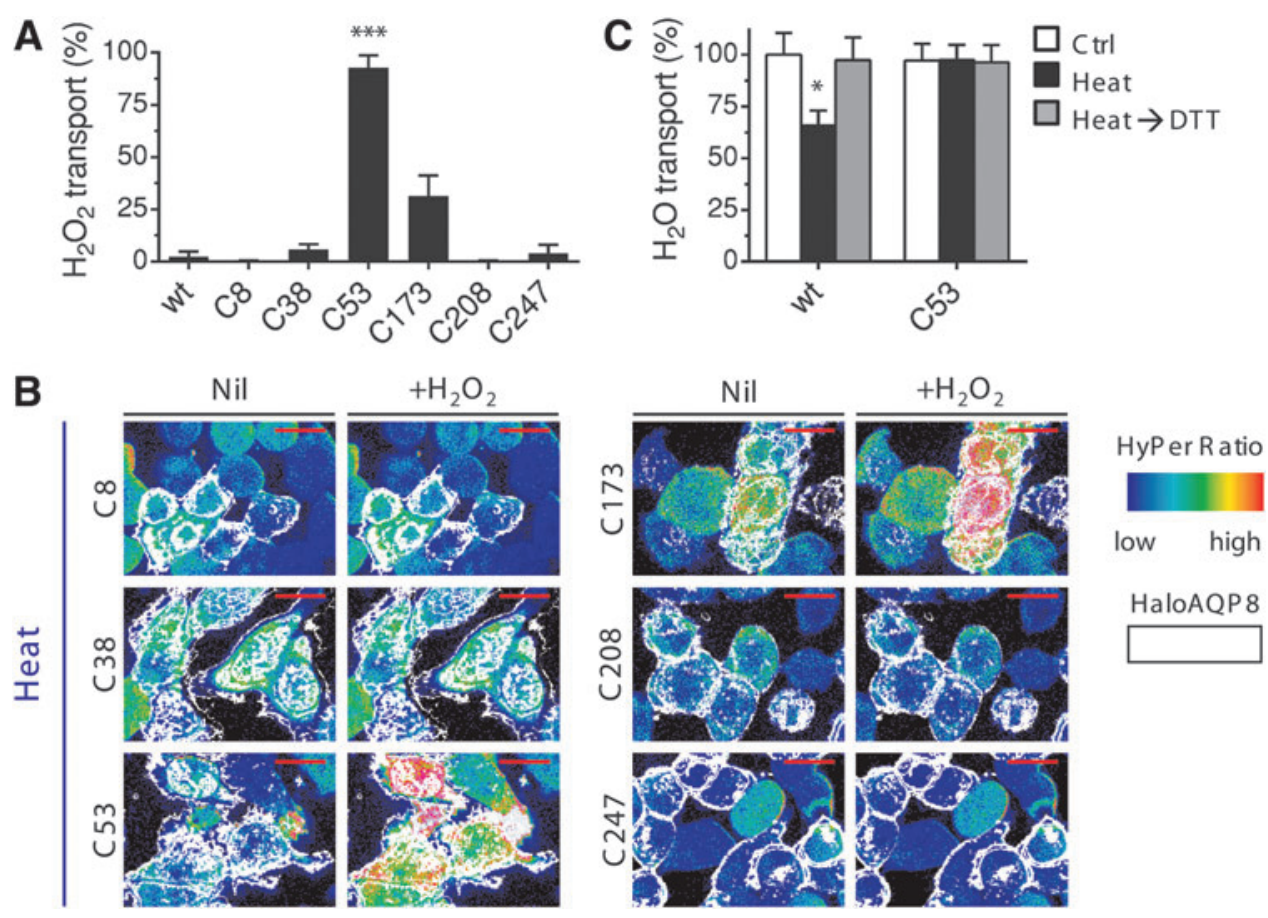

FIG. 3. The expression of AQP8 mutants impacts $\mathrm{H}_{2} \mathrm{O}_{2}$ and water transport. (A) Quantification of $\mathrm{H}_{2} \mathrm{O}_{2}$ transport after heat stress in HeLa cells expressing diverse AQP8 mutants at $90 \mathrm{~s}$ of addition of $50 \mu M$ of $_{2} \mathrm{O}_{2}$. The data are normalized to the cells expressing the HaloAQP8 wt recombinant protein in control conditions \pm SEM. (B). Frames extracted from a representative video of $\geq 3$ similar experiments, showing the kinetics of $\mathrm{H}_{2} \mathrm{O}_{2}$ import into HeLa cells stably expressing HyPerCyto (ratio in pseudocolor) and transfected with each of the six single-cysteine AQP8 mutants. See legend to Figure $2 \mathrm{~A}$ for more details. (C). Quantification of osmotic water permeability measured in stable wt- or C53S-expressing HeLa cells in control conditions (white bars) or after heat stress either with (gray bars) or without (black bars) a short treatment of DTT performed immediately before the analysis. Values are means of the initial rate constant $(\mathrm{K})$ of cell volume changes expressed as percentage of control cells \pm SEMs of $10-15$ single shots for each of $\geq 3$ different experiments. $* p<0.05 ; * * * p<0.001$. DTT, dithiothreitol. To see this illustration in color, the reader is referred to the web version of this article at www.liebertpub.com/ars

induced modifications of one or more of the six cysteine residues present in human AQP8 lead to the closure of the channels. If this were the case, mutating them could generate AQP8 variants that become insensitive to the stressdependent blockade. Therefore, we individually replaced the six cysteines in AQP8 for serine. Serine residues should retain the approximate size and geometry of cysteine residues, but be unable to form disulfide bonds or undergo other redox modifications affecting channel structure and conductivity. Accordingly, all single cysteine-to-serine replacements assayed were able to promote efficient water and $\mathrm{H}_{2} \mathrm{O}_{2}$ transport when expressed in yeast (Supplementary Fig. S3A, B), showing that mutating those residues did not hamper AQP8 activity in control conditions. HeLa cells were then transfected with wild-type (wt) HaloAQP8 or, separately, with the six mutants and the uptake of exogenous $\mathrm{H}_{2} \mathrm{O}_{2}$ evaluated before or after heat stress. Like in yeast, none of the cysteine mutants displayed significant impairment in $\mathrm{H}_{2} \mathrm{O}_{2}$ transport in control conditions in HeLa cells (data not shown). However, clear differences were evident when $\mathrm{H}_{2} \mathrm{O}_{2}$ import was analyzed after heat stress (Fig. 3A). In each sample, care was taken to average only cells expressing the transgenes, as detected by staining with fluorescent Halo ligands (Fig. 3B). In these experiments, negative cells served as powerful internal controls. Neither untransfected cells nor transfectants expressing wt, C8S, C38S, C208S, or C247S HaloAQP8 displayed $\mathrm{HyPeroxidation}$ upon exposure to $\mathrm{H}_{2} \mathrm{O}_{2}$. In con- trast, C53S transfectants were resistant to stress-induced inhibition (Fig. 3B, lower right two panels). A HyPerfluorescence shift was also patent in cells expressing C173S HaloAQP8 after $\mathrm{H}_{2} \mathrm{O}_{2}$ addition (Fig. 3B, upper right two panels), although this mutant was not as efficient as AQP8 C53S in rescuing the entry of $\mathrm{H}_{2} \mathrm{O}_{2}$ into heat-stressed HeLa cells (about $90 \%$ and $30 \%$ of the $\mathrm{H}_{2} \mathrm{O}_{2}$ transported by unstressed cells, respectively).

\section{Stress also inhibits the AQP8-dependent transport of water}

Like other aquaporins, AQP8 can transport water (22). Their expression allows fast changes in the cell volume upon exposure to osmotic gradients, which correspond to the kinetics of water transport across the plasma membrane (48). We therefore measured water fluxes in HeLa cells stably expressing HaloAQP8 wt or the C53S mutant by stoppedflow experiments (Fig. 3C). Staining with Halo ligands confirmed that $\geq 60 \%$ of the cells analyzed expressed the transgenes (data not shown). In agreement with our results on $\mathrm{H}_{2} \mathrm{O}_{2}$ import (Fig. 3A), water fluxes were similar in the two transfectants under control conditions (Fig. 3C, white bars). Remarkably, heat stress had a strong inhibitory effect on cells expressing HaloAQP8 wt, but not in C53S transfectants (Fig. 3C, black bars). Indeed, the latter were able to import water after stress as efficiently as in control conditions, suggesting that in HeLa cells, AQP8 is the main, if not the 
sole, target of stress-mediated water transport inhibition. This observation is further supported by the fact that in contrast with what was observed before for $\mathrm{H}_{2} \mathrm{O}_{2}$ transport, water transport was only partially inhibited in AQP8 wt-expressing HeLa cells, which express other water-transporting members of the AQP family not bearing the regulatory C53 residue, that is, AQP1 and AQP4 (data not shown). Of note, a short pretreatment with DTT was sufficient to restore permeability to water in cells expressing the stress-sensitive HaloAQP8 wt (Fig. 3C, gray bars) as observed when analyzing $\mathrm{H}_{2} \mathrm{O}_{2}$ transport. Thus, stress-induced redox-based mechanisms involving AQP8 inhibit the transport not only of $\mathrm{H}_{2} \mathrm{O}_{2}$ but also of water.

\section{Mechanisms of AQP8 inhibition}

Several mechanisms have been proposed to modulate transport through aquaporins, including oxidative gating and phosphorylation-dependent internalization from the plasma membrane $(25,43,47,59)$. We first considered the possible role of the latter in preventing AQP8-dependent transport. Unfortunately, our efforts to obtain trustworthy AQP8specific antibodies were unsuccessful. As a consequence, we followed the movements of HaloAQP8 by total internal reflection microscopy (TIRF) assays (3). By restricting the excitation to $90 \mathrm{~nm}$ below the plasma membrane, this technology allows visualizing only the basal region of cells ad- hered to glass slides. Intense fluorescence was detected in control cells, implying the presence of abundant HaloAQP8 molecules in the basal membrane. However, no significant differences could be recorded between control and heatstressed cells (Supplementary Fig. S4A). As the resolution of TIRF cannot formally exclude AQP8 internalization, we generated a recombinant AQP8 protein, in which an myc tag was inserted in the first extracellular loop (HaloAQP8 mycout). The capability of this protein to transport water or $\mathrm{H}_{2} \mathrm{O}_{2}$ was verified in yeast (Supplementary Fig. S3A, B). As revealed by quantitative cytofluorometric analyses, the binding of myc-specific antibodies was not significantly perturbed upon exposure of HeLa transfectants to heat shock (Supplementary Fig. S4B). Taken together, these data indicated that stress-induced inhibition of $\mathrm{H}_{2} \mathrm{O}_{2}$ and water transport is not due to internalization of AQP8.

In view of the critical role of cysteines 53 and (to a lesser extent) 173 , we then sought evidence for redox modifications of the channel proteins. Nonreducing gels did not show proof of inter- or intrachain disulfide bonds (Supplementary Fig. S5A). Dimedone-based chemical probes $(41,46)$ were used then to verify whether C53 was a target of sulfenylation. Although the amount of sulfenylated proteins increased in cells treated with increasing concentrations of $\mathrm{H}_{2} \mathrm{O}_{2}$ (Supplementary Fig. S5B), we could not obtain compelling evidence for oxidative modifications directly or indirectly
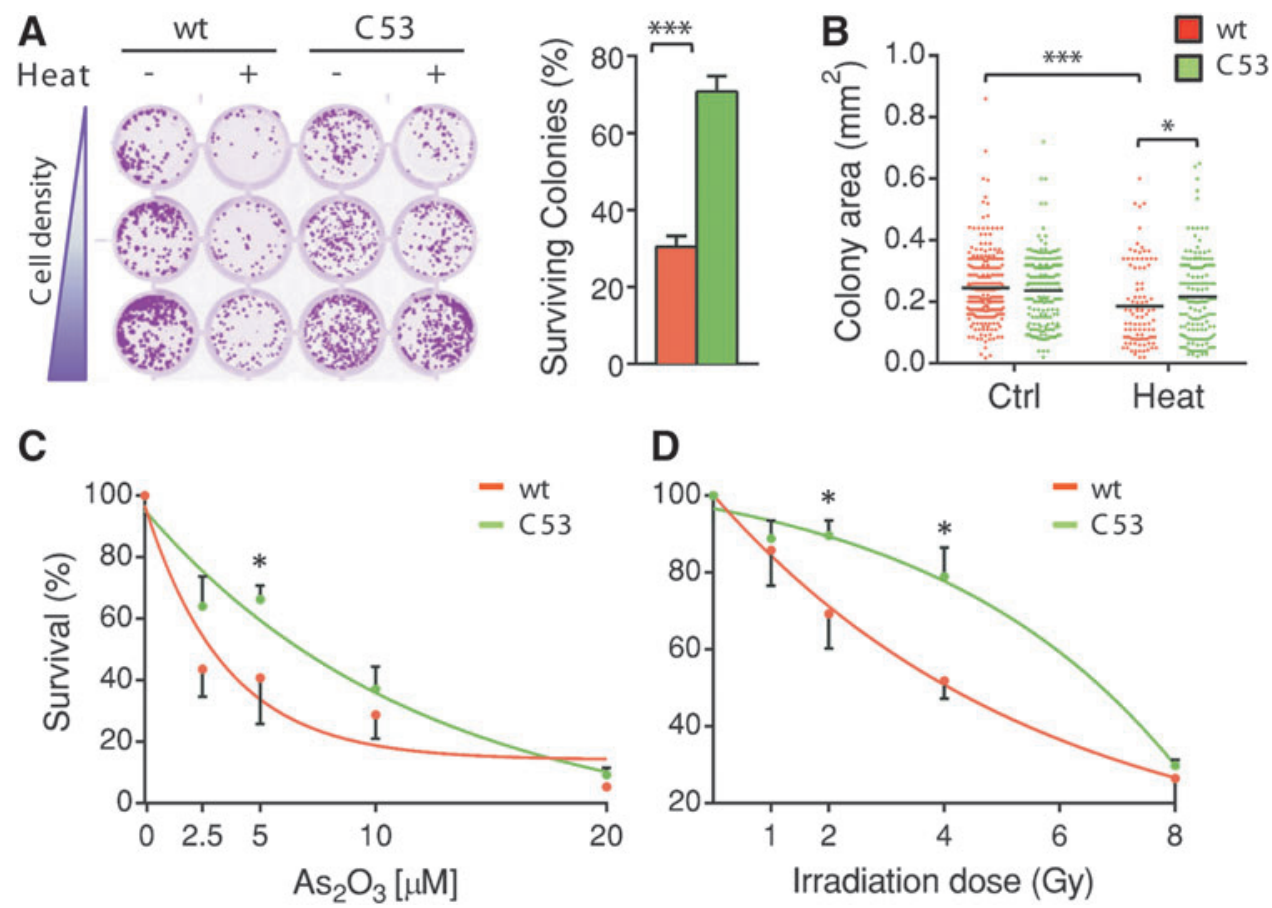

FIG. 4. Expression of C53S AQP8 confers stress resistance to HeLa cells. (A) Clonogenic assays comparing the ability of stable HaloAQP8 wt- or C53S-expressing HeLa cells to form clonal colonies before and after heat stress. Wells are the result of twofold serial dilutions to allow visualization of single-cell-derived colonies. Results are represented as percentage of surviving colonies. Average of three experiments \pm SEM. (B). Measurement of colony area distribution in both AQP8 wt and C53Sexpressing HeLa cells before and after the stress. Each dot represents a single colony and its area is displayed in $\mathrm{mm}^{2}$. $(\mathbf{C})$. Quantification of the clonogenic capacity of stable HaloAQP8 wt and C53S-expressing HeLa cells after 7 days from irradiation with different doses. Data are represented as percentage of surviving colonies with respect to the number of colonies grown in control conditions \pm SEM. (D). Quantification of the clonogenic capacity of stable HaloAQP8 wt and C53S-expressing HeLa cells after 7 days from a 24 h-treatment with the indicated doses of arsenic trioxide. Data are represented as in $(\mathbf{C})$. ${ }^{*} p<0.05$; $* * * p<0.001$. To see this illustration in color, the reader is referred to the web version of this article at www.liebertpub.com/ars 
impacting AQP8 (Supplementary Fig. S5B, C). Of note, a clear increase in the amount of intracellular sulfenylated proteins was evident in cells exposed to elevated temperature (Supplementary Fig. S5C). This increase was less pronounced in cells expressing $\mathrm{C} 53 \mathrm{~S}$.

\section{Inhibition of AQP8-mediated transport determines cell fate after stress}

Whether stress culminates in survival or death is determined by different factors, such as its intensity and duration, the cell type, and other environmental cues (16). To ascertain whether AQP8-mediated transport can impact the cellular responses to stress, we compared several key physiological parameters in HeLa cells stably expressing HaloAQP8 wt or the C53S mutant (Fig. 4). Crystal violet-based clonogenic assays were used to measure proliferation and/or cell survival as counting the number and size of colonies obtained after plating cells before or after exposure to stress provides an estimate of stress resistance. Consistent with the previous results, no significant differences were observed when HaloAQP8 wt or C53S transfectants were cultured in control conditions. However, the expression of the noninhibitable AQP8 variant (C53S) rendered cells more able to survive a severe heat stress than did wt channels (Fig. 4A). The C53S transfectants yielded about $70 \%$ of the colonies obtained by plating unstressed cells, while only $30 \%$ were recovered in cells expressing HaloAQP8 wt. Of note, similar percentages of colonies were obtained at the three different cell concentrations, arguing against cell cooperativity in the resistance to stress. The size of colonies roughly depends on the number of divisions that a cell undergoes after having successfully attached to the plate. C53S-expressing cells formed slightly but significantly larger colonies than cells expressing the wt protein (Fig. 4B). Thus, maintaining open AQP8 channels confers adaptive advantages, allowing cells to grow also when they are subjected to harsh conditions.

It is generally accepted that radiotherapy, as well as most chemotherapeutic drugs, kills neoplastic cells by inducing a lethal oxidative stress $(54,60)$. To investigate whether C53S expression confers a surviving advantage to cells exposed to established antitumor therapies, we performed clonogenic assays after either $\mathrm{X}$-irradiation or treatment with arsenic trioxide $\left(\mathrm{As}_{2} \mathrm{O}_{3}\right)$. As shown in Figure $4 \mathrm{C}$ and $\mathrm{D}$, cells expressing AQP8 C53S are more resistant to either treatment than the wtexpressing ones. Therefore, dysregulation of AQP8 permeability may represent a protective mechanism activated by cells against endogenous or exogenous stressful stimuli.

\section{Expression of C53S counteracts stress-induced growth arrest}

The smaller size of the colonies recovered after heat shock (Fig. 4B) is in line with the notion that severe stresses cause transient growth arrest (10). To further investigate the role of AQP8, we compared cells expressing wt or C53S variants for their efficiency in replenishing an empty territory (Fig. 5A and Supplementary Movies S3-S6). In principle, these gapfilling assays measure the combined rates of cell division and motility, but owing to the proliferative capabilities of HeLa cells, the former prevail in our experimental setting, despite the use of low serum concentrations. In addition, in these experiments, no significant differences were observed between untreated wt- and C53S-expressing cells (see quantifications in Fig. 5A). Instead, after heat stress, gap closure started sooner and was significantly more efficient in cells

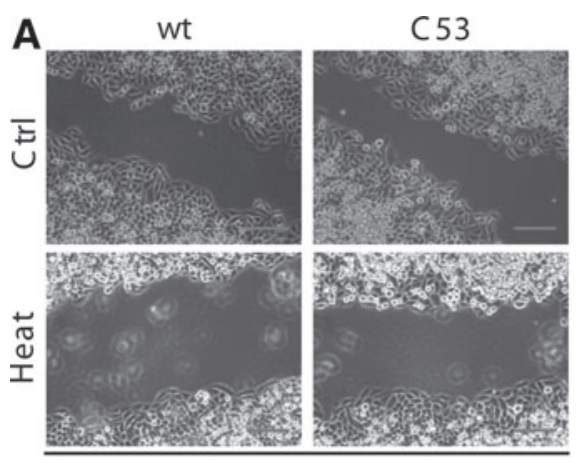

24 hours

B

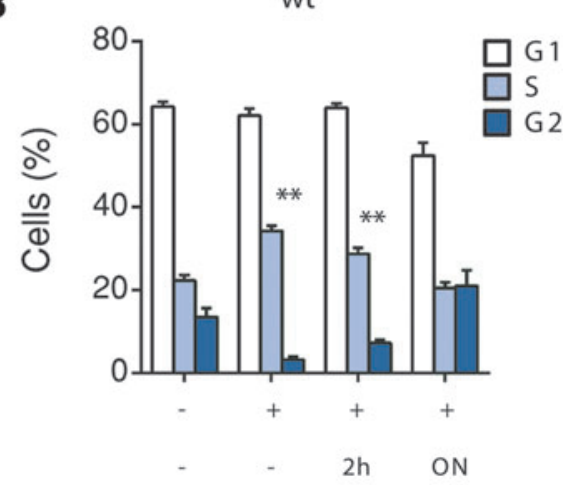

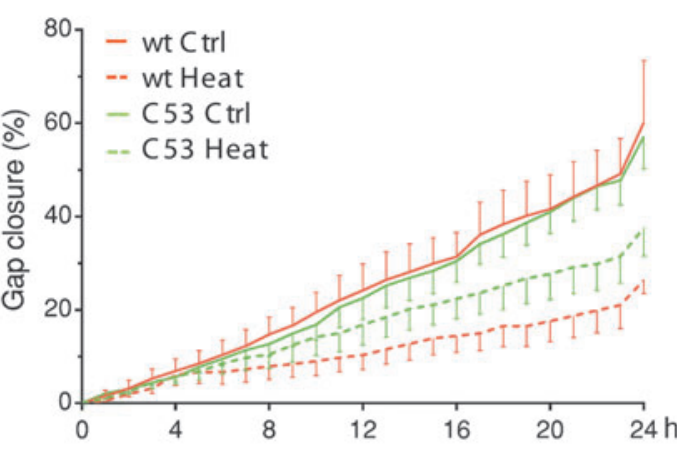

C53

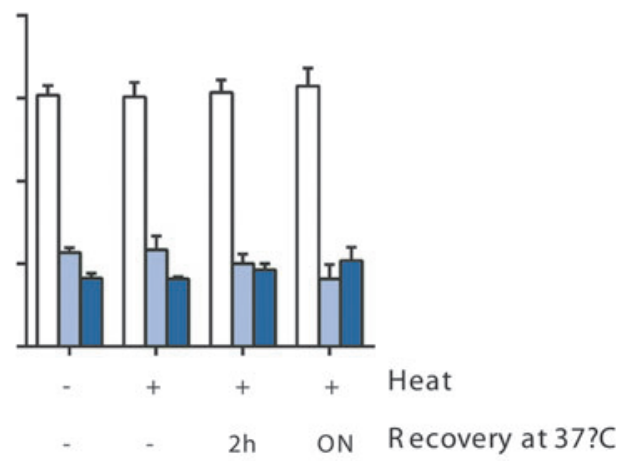

FIG. 5. AQP8 inhibition by stress causes reversible growth arrest. (A) The images show frames of a representative video taken at time 0 or after $24 \mathrm{~h}$ of culture at $37^{\circ} \mathrm{C}$, in which HaloAQP8 wt- or AQP8 C53Sexpressing cells fill a $500 \mu \mathrm{m}$ gap, before or after a 3-h heat stress. Scale bars correspond to $200 \mu \mathrm{m}$. The results of $\geq 3$ independent experiments are averaged on the right panel and represented as percentage of gap closure against time \pm SEM. (B). Cell cycle phase distribution of AQP8 wt- or AQP8 C53S-expressing cells was compared before, immediately after heat stress, or after further 2-h or overnight incubation at $37^{\circ} \mathrm{C}$, as indicated. Data are represented as the percentage of cells in each phase relative to the total cell number (average of three experiments \pm SEM). $* * p<0.01$. ON, overnight. To see this illustration in color, the reader is referred to the web version of this article at www.liebertpub.com/ars 
A
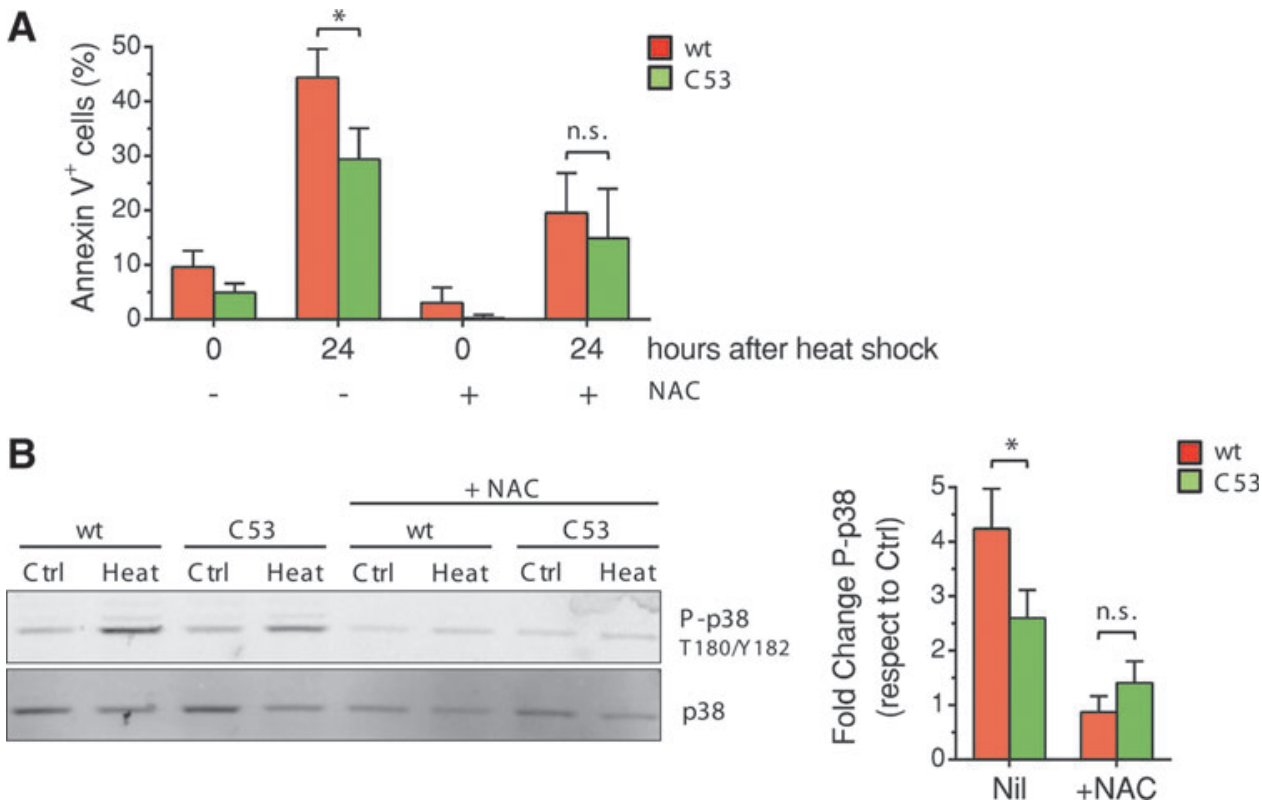

FIG. 6. AQP8 mutation in C53S influences stress-induced p38 phosphorylation. (A) Apoptosis in stable HaloAQP8 wt and C53S-expressing HeLa cells was monitored by Annexin-V staining, both immediately after inducing stress with or without $2 \mathrm{mM}$ NAC or after $24 \mathrm{~h}$ of culture at $37^{\circ} \mathrm{C}$. Data are expressed in percentage of Annexin-V-positive cells \pm SEM. (B). The image shows a representative Western blot analysis, showing changes in phosphorylation of p38 on whole HeLa cell extracts. Cells stably expressing HaloAQP8 wt or C53S mutant were cultured for $3 \mathrm{~h}$ at $37^{\circ} \mathrm{C}$ or $42^{\circ} \mathrm{C}$ with or without $2 \mathrm{mM}$ NAC. The right panel shows the quantification of phospho-p38 signal normalized against its total levels. Data are represented as fold change of p38 phosphorylation under stress conditions with respect to the signal obtained with unstressed controls. Average of eight experiments \pm SEM. $* p<0.05$. n.s., non significant. To see this illustration in color, the reader is referred to the web version of this article at www.liebertpub.com/ars

expressing C53S, strongly suggesting that these cells were less sensitive to growth arrest in response to stress. Cell cycle analyses confirmed that AQP8 wt-expressing cells were arrested in the $\mathrm{S}$ phase (Fig. 5B, left panel). In contrast, the consequent increase in the S/G2 ratio was not observed in cells expressing the noninhibitable AQP8 C53S mutant (Fig. 5B, right panel). Stable transfectants producing AQP8 wt recombinant proteins were able to resume growth after incubation at $37^{\circ} \mathrm{C}$, indicating that the stress-derived proliferative block is reversible and can be overcome if the duration or strength of the stress is limited (Fig. 5B, left panel).

\section{Expression of AQP8 C53S limits stress-induced signaling and apoptosis.}

Next, we investigated whether the expression of a noninhibitable AQP8 protects cells from damage-induced cell death. Staining with Annexin-V (56) confirmed that expression of HaloAQP8 C53S conferred resistance to stress-induced apoptosis. The percentage of Annexin-V-positive cells was lower in AQP8 C53S than in wt transfectants either immediately upon stress or after $24 \mathrm{~h}$ of recovery at $37^{\circ} \mathrm{C}$ (Fig. 6A). These results mirror the lower efficiency of cells expressing AQP8 wt in gap-filling assays (see quantification in Fig. 5A).

It is well established that different stress conditions cause phosphorylation of $\mathrm{p} 38$ via circuits involving ROS production (55). Accordingly, phosphorylation of p38 was increased over fourfold upon heat stress in HeLa transfectants expressing wt AQP8 (Fig. 6B), but to a lesser extent in cells expressing C53S (compare lanes 1-4 and the quantification of eight independent experiments on the right). As expected, addition of NAC during temperature stress prevented $\mathrm{p} 38$ phosphorylation (lanes 5-6). p38 phosphorylation was partially inhibited by NAC also in C53S mutants, possibly because only $60 \%$ of cells express the mutant protein. NAC was also able to reduce the differences in stress-induced apoptosis between AQP8 wt- and C53S-expressing cells (Fig. 6A). The higher activation of $\mathrm{p} 38$ in AQP8 wt cells correlates with the higher levels of apoptotic cells in stressed AQP8 wt-expressing cells, which is consistent with the known role of activated p38 as inducer of apoptosis (55). Along this line, the lower phosphorylation of p38 in AQP8 C53S-expressing cells is in accordance with their increased viability, in part, providing a plausible explanation of the stress-resistant phenotype.

Finally, we investigated whether AQP8 wt- and C53Sexpressing cells differed in their sensitivity to hypoxia, a condition known to generate intracellular ROS (20). Cells expressing the noninhibitable C53S mutant accumulated less HIF $1 \alpha$ after $24 \mathrm{~h}$ of culture at $1 \%$ oxygen (Supplementary Fig. S6A), in consonance with the possibility that permeant AQP8 channels allow extrusion of excess ROS, limiting their accumulation (Supplementary Fig. S4C and Fig. 7) and consequently HIF $1 \alpha$ stabilization. Expression of AQP8 C53S allowed cells to form bigger colonies when cultured after hypoxic stress (Supplementary Fig. S6B), in line with our finding (Fig. 4B) that nonrestrained $\mathrm{H}_{2} \mathrm{O}_{2}$ transport across the plasma membrane confers growth advantages.

\section{Discussion}

In this study, we show that the transport of both $\mathrm{H}_{2} \mathrm{O}_{2}$ and water through AQP8 is inhibited following diverse cellular stresses. Mutation of conserved cysteine residues in AQP8 confers resistance to stress. These observations, together with 

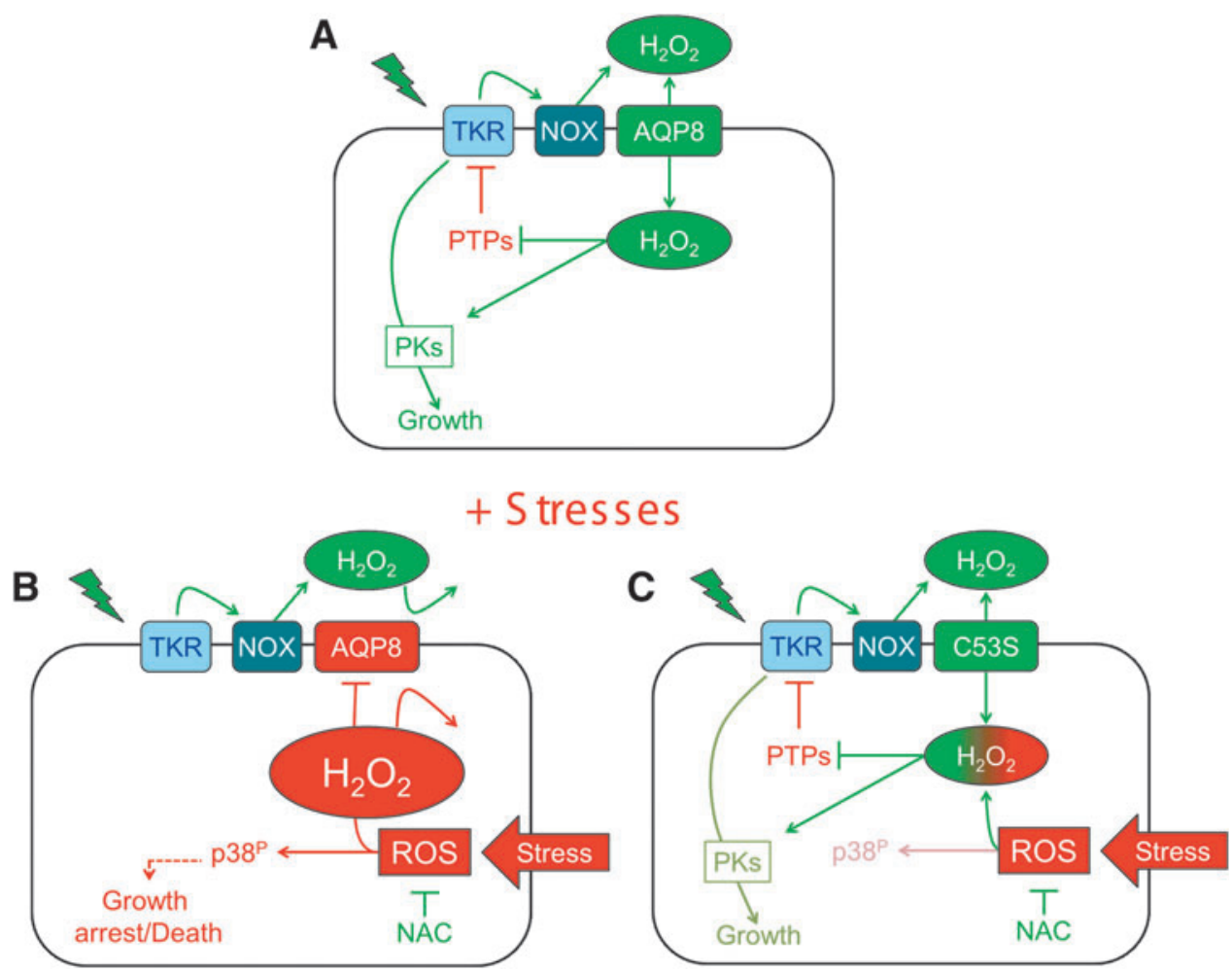

FIG. 7. Schematic model of $\mathrm{H}_{2} \mathrm{O}_{2}$ generation and transport during signaling. Membrane NOX and DuOX enzymes are activated upon TKR engagement to produce $\mathrm{H}_{2} \mathrm{O}_{2}$, which enters the cells via AQP8 and amplifies downstream signaling (A). Under stress conditions, redox-dependent modifications inhibit $\mathrm{H}_{2} \mathrm{O}_{2}$ transport. Consequently, TKR-dependent phosphorylation cascades are downregulated and apoptosis is promoted through ROS-dependent p38 activation (B). In contrast, the presence of noninhibitable AQP8 (C53S) restores transport and leads to a stress-resistant phenotype (C). The stressinduced proapoptotic and $\mathrm{H}_{2} \mathrm{O}_{2}$ growth-promoting events are depicted in red and green, respectively, highlighting the dichotomous $\mathrm{H}_{2} \mathrm{O}_{2}$ effects. NOX, NADPH oxidase; TKR, tyrosine kinase receptor. To see this illustration in color, the reader is referred to the web version of this article at www.liebertpub.com/ars

the finding that stress-mediated inhibition of AQP8 wt is prevented by reducing agents, sustain the redox dependency of the regulatory mechanisms and provide key information on its target. Importantly, substitution of AQP8 cysteine residues does not impact protein activity in basal conditions. In contrast, the role of cysteines 53 and (to a lesser extent) 173 in modulating channel function under stress is compelling, although the underlying molecular mechanisms are only partially clarified. In fact, we demonstrated that different stresses converge in gating AQP8-mediated $\mathrm{H}_{2} \mathrm{O}_{2}$ transport via reversible modifications that preferentially target C53, directly or indirectly, and that DTT recovers the activity of stressed AQP8.

Because of their reactivity, only functional cysteines tend to be conserved during evolution $(37,49)$. Thus, the presence of C53-like residues in AQP8 and AQP3, both known to transport $\mathrm{H}_{2} \mathrm{O}_{2}(6,39)$, points to relevant role(s) of these cysteines as redox regulatory switches. Computational predictions of the AQP8 structure (obtained by homology modeling on the web server SWISS-MODEL (2) using the Uniprot entry for human AQP8 O94778) argue against the formation of disulfide bridges between C53 and C173. Accordingly, we did not detect intra- or intermolecular disulfide linkages in AQP8 upon stress. However, the vicinity of R213 could favor C53 deprotonation, rendering it a target of oxidative post-translational modifications, such as sulfenylation, persulfidation, or nitrosation. It is also possible that other molecules are modified so as to inhibit AQP8 in a C53dependent manner. Care was taken to exclude the internalization of AQP8, a mechanism utilized to remove other aquaporins from the plasma membrane and often induced by phosphorylation $(43,47)$. Interestingly, also water transport through AQP8 wt, but not the C53S mutant, is inhibited by stress and is recovered by exposure to reducing agents. The finding that water fluxes are also blocked by stress further confirms that redox-dependent circuits targeting C53 modulate AQP8 activity and excludes artifactual modifications of the redox-sensitive $\mathrm{HyPerCyto}$ probe due to $\mathrm{H}_{2} \mathrm{O}_{2}$ transport.

Our results also show that the stress-dependent gating of AQP8 has important consequences on the outcome of stress. Severe stress is followed by growth arrest and cell death, which limits proliferation of damaged or transformed cells. Stresses most often induce intracellular production of ROS. In this scenario, blocking AQP8-dependent transport can provide a dual defense against oxidative damage: if the stress is mild, cells resume growth once the problem is solved; if it is harsh, cells undergo apoptosis, limiting the deleterious effects of ROS at the organism level. Cells expressing the noninhibitable AQP8 C53S variant are more resistant to stress-induced growth arrest and ROS-triggered apoptosis, thus increasing survival. Stress-induced inhibition of water transport may also contribute to the cell responses to stresses: in this regard, a recent report shows that knocking down AQP2 or AQP4 
impacts water transport, resulting in an increase of survival in nematodes during hypotonic-anoxic stress (30).

Figure 7 summarizes a plausible scenario emerging from our results. In normal conditions (Fig. 7A), growth factor stimulation activates NOXes to produce $\mathrm{H}_{2} \mathrm{O}_{2}$ that reaches its cytosolic targets via AQP8 or other channels $(6,39)$. The downstream protein kinase $(\mathrm{PK})$ circuits promote proliferation. In contrast, severe stress can induce apoptosis via the Ask1-p38 phosphorylation pathway (Fig. 7B). This is an ROS-dependent event (55), which can be prevented by the addition of NAC during stress. Gating of AQP8 impedes the bidirectional transport of $\mathrm{H}_{2} \mathrm{O}_{2}$ (1), yielding two important consequences. On the one hand, NOX-derived $\mathrm{H}_{2} \mathrm{O}_{2}$ cannot exert its growth-promoting effects. On the other, the excess of $\mathrm{H}_{2} \mathrm{O}_{2}$ produced intracellularly upon stress cannot be extruded through AQP8, facilitating growth arrest and apoptosis. The expression of AQP8 C53S (Fig. 7C) allows cells to proliferate sooner after stress because they can eliminate the excess of $\mathrm{H}_{2} \mathrm{O}_{2}$ and/or still uptake the molecule to promote growth. To explain the coexistence of opposite redox pathways, the model implies that signaling outcome is controlled either by the dose or the duration of $\mathrm{H}_{2} \mathrm{O}_{2}$ production and that topological and/or biochemical restraints limit its diffusion in the cytoplasm. Accordingly, it has been shown that receptor stimulation locally inactivates peroxiredoxin-1 (Prx1), spatially allowing $\mathrm{H}_{2} \mathrm{O}_{2}$-driven signal amplification (58). Although a fraction of AQP8 has been reported to localize to mitochondria (9), in our hands, AQP8 silencing had little if any effect on $\mathrm{H}_{2} \mathrm{O}_{2}$ transport across the membrane of these organelles (6), suggesting that in this context, stress does not target mitochondrial AQP8. Probes capable of dissecting $\mathrm{H}_{2} \mathrm{O}_{2}$ diffusion within the cytosol with improved resolution are needed to pursue this exciting line of investigation.

Cancer cells often experience stressful conditions, such as hypoxia, low $\mathrm{pH}$, or starvation, which increase ROS production (33). In conflict with the traditional view, a number of recent studies have shown that while the increase of ROS often causes severe damage and cell death, overexpression of antioxidant defenses is itself a direct promoter of cancer development and progression and is responsible for drug resistance $(14,19)$. Our clonogenic assays indicate that the inability of gating AQP8 upon stress, due to mutation in the C53 residue, not only causes increased survival but also results in resistance to pro-oxidant anticancer treatments (45). In addition, reduced sensitivity to hypoxia might be due to the capacity of stressed cells expressing a noninhibitable AQP8 to get rid of excess ROS. In this way, ROS intracellular accumulation and the consequent cell damage and apoptosis are prevented. This is particularly important in cancer cells, where the ability to cope with elevated ROS levels limits many therapeutic approaches. Thus, characterizing the mechanisms that inhibit the activity of AQP8 and identifying protocols to modulate them may open the way to unforeseen therapeutic opportunities.

\section{Materials and Methods}

\section{Cell culture}

HeLa cells were cultured in DMEM+Glutamax ${ }^{\mathrm{TM}}-\mathrm{I}$ medium (Life Technologies) supplemented with $10 \%$ fetal bovine serum (FBS; EuroClone) and $5 \mathrm{mg} / \mathrm{ml}$ penicillinstreptomycin (Lonza).

\section{Plasmids, siRNAs, and transfection procedures}

The plasmid for expression of the HyPerprobe targeted to the cytosol (HyPerCyto) was a generous gift of Dr. V. Belousov (IBCh, Moscow, Russian Federation), while silencingresistant Halo-AQP8 (HaloAQP8) plasmid was generated as previously described (6) and used as a template to create the single-cysteine mutants by site-directed mutagenesis using the following primers: HaloAQP8 C8S: Fw - 5' GATAGCCATG TCTGAGCCTGAATTTGGC 3', Rv - 5' GCCAAATTCAGG CTCAGACATGGCTATC 3'; HaloAQP8 C38S: Fw 5' - GTG CAGCCATCTCTGGTCGAAC 3', Rv - 5' GTTCGACCAGA GATGGCTGCAC 3'; HaloAQP8 C53S: Fw 5' - CTTCATC GGGTCCCTGTCGGTC 3', Rv - 5' GACCGACAGGGACC CGATGAAG 3'; HaloAQP8 C173S: Fw 5' - CCTGGCTGT ATCCATGGGTGCC 3', Rv - 5' GGCACCCATGGATACA GCCAGG 3'; HaloAQP8 C208S: Fw 5' - GTCTGGAGGCT CCATGAATCCC 3', Rv - 5' GGGATTCATGGAGCCTCC AGAC 3'; and HaloAQP8 C247S: Fw 5' - GCTCATTAGG TCCTTCATTGGAGATGGG 3', Rv - 5' CCCATCTCCAA TGAAGGACCTAATGAGC 3'. All constructs were validated by sequencing.

The AQP8 insert, including an myc tag in the first extracellular loop (loop A) and flanked by two glycines to confer flexibility, was synthetized by Eurofins Genomics. HaloAQP8 myc-out-expressing plasmid was constructed by cloning the synthetic insert into the pHTN-HaloTag ${ }^{\circledR}$ vector (Promega).

The AQP8-specific siRNA oligonucleotide (5' UUUGG CAAUGACAAGGCCA 3') and an unrelated control (Block$\mathrm{it}^{\mathrm{TM}}$ ) were purchased from Ambion (Life Technologies) and their efficiency monitored by real-time RT-PCR as reported before (6).

For silencing experiments, $8 \times 10^{4}$ HyperCyto-expressing HeLa stable transfectants (See "Generation of stable HeLa cell lines") were grown overnight in six-well plates and transfected with 90 pmol of siRNA, using RNAiMAX lipofectamin (Invitrogen), according to the manufacturer's instructions. Cells were analyzed for efficient silencing and used after $72 \mathrm{~h}$ of transfection.

For experiments in which AQP8 expression was reconstituted transiently using HaloAQP8-wt or the mutant recombinant proteins, cells were first silenced for $24 \mathrm{~h}$ and then transfected by polyethylenimine (PEI) (8) and cultured for further $48 \mathrm{~h}$ before imaging or biochemical analyses.

\section{Generation of stable HeLa cell lines}

HeLa transfectants stably expressing either HyPerCyto, HaloAQP8 wt, or HaloAQP8 C53S, were generated by PEI transfection.

After 4 days in selection with $0.5 \mathrm{mg} / \mathrm{ml}$ of G418 (Sigma), HeLa-HyPerCyto cells were directly sorted at 488 and $405 \mathrm{~nm}$ using an MoFlo XDP cell sorter (Beckman Coulter). To obtain HeLa transfectants stably expressing HaloAQP8 wtand HaloAQP8 C53S, cells were stained overnight with $2 \mathrm{n} M$ of HaloTag TMR Direct Ligand (Promega) and sorted at $534 \mathrm{~nm}$.

\section{Reagents and stress treatments}

Tunicamycin, 2-deoxyglucose, and geldanamycin were purchased from Sigma and used at the final concentrations of $10 \mu \mathrm{g} / \mathrm{ml}$ for $4 \mathrm{~h}, 6 \mathrm{~m} M$ overnight, and $1 \mu M$ overnight, respectively. Arsenic trioxide $\left(\mathrm{As}_{2} \mathrm{O}_{3}\right)$ was a generous gift of 
Dr. Rosa Bernardi (IRCSS San Raffaele) and was incubated overnight at $37^{\circ} \mathrm{C}$ at the indicated concentrations.

Heat shock treatment was performed by putting the plates, each containing $1.8 \times 10^{6}$ cells in $2 \%$ FBS medium, in a water bath set at $42^{\circ} \mathrm{C}$ with or without $10 \mu M$ diphenyleneiodonium (DPI; Sigma) or with $2 \mathrm{mM}$ of N-acetyl-cysteine (NAC; Sigma). After $3 \mathrm{~h}$ at $42^{\circ} \mathrm{C}$, cells were either lysed for biochemical assays or utilized for live imaging or FACS analyses.

Cell irradiation was performed in a Biobeam gammairradiator device (Gamma-service Medical Gmbh) using the preprogrammed manufacturer setups for the indicated gray (Gy).

Hypoxic conditions were induced either by culturing the cells for $3 \mathrm{~h}$ or $24 \mathrm{~h}$ at $1 \%$ oxygen in a hypoxia workstation (Invivo2 400; Ruskinn Technology, Ltd.).

\section{Imaging HyPeroxidation}

To perform confocal live imaging experiments, $8 \times 10^{4}$ HyperCyto-expressing HeLa cells were silenced and/or transfected on glass coverslips as described above. To identify HaloAQP8-expressing cells, $2 \mathrm{n} M$ HaloTag TMR Direct Ligand was added $24 \mathrm{~h}$ after transfection. After $24 \mathrm{~h}$ of culture with the fluorescent ligand, cells on coverslips were equilibrated in Ringer Buffer (RB: $140 \mathrm{~m} M \mathrm{NaCl}, 2 \mathrm{~m} M \mathrm{CaCl}_{2}$, $1 \mathrm{~m} M \mathrm{MgSO}_{4}, 1.5 \mathrm{mM} \mathrm{K} \mathrm{HPO}_{4}, 10 \mathrm{~m} M$ Glucose, $\mathrm{pH}$ 7.3) for $10 \mathrm{~min}$ at room temperature (RT) before addition of $50 \mu \mathrm{M}$ of $\mathrm{H}_{2} \mathrm{O}_{2}$ or $5000 \mathrm{U} / \mathrm{ml}$ extracellular catalase (both from Sigma), all freshly prepared in RB. When indicated, cells were equilibrated for $5 \mathrm{~min}$ in RB and then treated for $5 \mathrm{~min}$ with $5 \mathrm{mM}$ DTT (Sigma) diluted in RB, washed, and analyzed.

Confocal images were collected every $2 \mathrm{~s}$ for $3 \mathrm{~min}$ or more by dual excitation with $488 \mathrm{~nm}$ argon and $405 \mathrm{~nm}$ violet diode lasers. We used an Ultraview confocal laser scanning microscope equipped with a $40 \times$ oil immersion lens (Perkin Elmer). The $488 / 405 \mathrm{~nm}$ ratios were calculated by ImageJ software for $\geq 25$ cells, averaged, and are shown as mean fold change ratio plotted against time \pm SEM. Alternatively, we averaged the data obtained after $90 \mathrm{~s}$ from $\mathrm{H}_{2} \mathrm{O}_{2}$ addition in the time course experiments performed and represented them as the percentage of $\mathrm{H}_{2} \mathrm{O}_{2}$ transport in stressed cells relative to the corresponding nonstressed cells to facilitate quantification and statistical analyses. At least three independent experiments were performed for each condition and/or mutant, except for nonstressed cells treated with NAC and mutant AQP8 C8S-stressed cells, in which two different experiments gave almost identical results.

\section{Stopped-flow experiments}

Osmotic water permeability was measured by the stoppedflow light scattering method as described before (28). Briefly, HeLa-HaloAQP8 wt and -HaloAQP8 C53S were seeded in culture flasks and grown until they reached approximately $90 \%$ confluence. Cells were scraped off from the flasks and incubated at $37^{\circ} \mathrm{C}$ or $42^{\circ} \mathrm{C}$ for $3 \mathrm{~h}$ and then treated with or without DTT. Then, cells were centrifuged, resuspended in Hank's solution, and used for the osmotic permeability measurements. The analysis of cell swelling caused by exposure to a hypotonic gradient $(150 \mathrm{mosm} / \mathrm{L})$ was performed on a stopped-flow apparatus (RX2000; Applied Photophysics) with a pneumatic drive accessory (DA.1; Applied Photophysics) coupled with a Varian Cary 50 spectrometer
(Varian Australia Pty. Ltd.). Scattered light intensity at RT with a dead time of $6 \mathrm{~ms}$ was recorded at a wavelength of $450 \mathrm{~nm}$. The time course of swelling was measured for $60 \mathrm{~s}$ at the acquisition rate of one reading $/ 0.0125 \mathrm{~s}$. The gradient caused osmotic water influx, cell swelling, and decreased light scattering. The initial rate constant of cell volume changes (k) was obtained by fitting the time course of light scattering with a one-phase exponential decay up to $12 \mathrm{~s}$ (GraphPad Prism 4.00, 2003). Results are represented as percentage of water transport under stressed conditions relative to the transport in control conditions \pm SEM. All experiments were performed at least thrice.

\section{Clonogenic assay}

The colony-forming ability of HeLa cells stably expressing HaloAQP8 wt or mutant C53S was assessed before or after stress. Briefly, cells were incubated in p35 plates at $37^{\circ} \mathrm{C}$ or $42^{\circ} \mathrm{C}$, treated with arsenic trioxide, irradiated or cultured in $1 \%$ oxygen as described above, carefully counted, and subsequently reseeded in a 24-well plate at serial twofold dilutions starting from 5000 cells/well. Once plated, cells were placed at $37^{\circ} \mathrm{C}$ and incubated there for 7 days, a time corresponding to six potential cell divisions. After that period, cells were stained with crystal violet (44). Briefly, wells were washed once with PBS and cells were fixed with $2 \%$ formaldehyde for $10 \mathrm{~min}$ before permeabilization with $2 \%$ methanol for $10 \mathrm{~min}$ at RT. Then, the colonies were stained with $0.2 \%$ crystal violet for $5 \mathrm{~min}$ at RT with gentle shaking. All of these reagents were from Sigma. Wells were washed with distilled water until a clear background was visible and left to dry at RT for $24 \mathrm{~h}$. Resulting colonies were scanned, counted, and their individual areas measured using the colony counter ImageJ plug-in. The percentages of colonies formed by stressed cells were calculated relative to unstressed cells and the resulting averages are shown \pm SEM. When indicated, averaged data were interpolated with a nonlinear regression (curve fit) analysis using Prism software. The area of individual colonies was represented using a distribution graph and expressed in $\mathrm{mm}^{2}$. For heat shock and $\mathrm{As}_{2} \mathrm{O}_{3}$ treatment clonogenic assays, three independent experiments were performed and $n \geq 2$ wells were counted. For X-irradiation treatment, two different experiments gave consistent results and $n \geq 2$ wells were counted. For the hypoxic treatment, one experiment was performed and $n \geq 3$ wells were counted.

\section{Apoptosis and cell cycle analyses}

Subconfluent HeLa cultures (60-90\%) were synchronized by culturing them in DMEM at low (2\%) FBS concentrations for $3 \mathrm{~h}$ at $42^{\circ} \mathrm{C}$ or $37^{\circ} \mathrm{C}$ with or without $2 \mathrm{mM}$ of NAC and stained with Annexin- $\mathrm{V}$ following the protocol provided by the manufacturer (eBioscence) soon after stress or $24 \mathrm{~h}$ after recovery at $37^{\circ} \mathrm{C}$. Data were acquired in an FACSCanto cytometer (BD Biosciences), analyzed with FCS Express 4 Flow software (De Novo Software), and represented as a percentage of Annexin-V-positive cells \pm SEM. Experiments were performed at least three independent times. For cell cycle analyses, HaloAQP8 wt or HaloAQP8 C53S stable transfectants were stained with propidium iodide (PI) immediately after stress or after either a 2-h or overnight recovery at $37^{\circ} \mathrm{C}$. Briefly, cells were washed twice with PBS without $\mathrm{Ca}^{++} / \mathrm{Mg}^{++}$ (EuroClone), fixed in $70 \%$ cold ethanol, incubated in $0.5 \mathrm{ml}$ of 
PBS without $\mathrm{Ca}^{++} / \mathrm{Mg}^{++}$supplemented with $50 \mu \mathrm{g} / \mathrm{ml} \mathrm{PI,} 0.1 \%$ sodium citrate, and $50 \mu \mathrm{g} / \mathrm{ml}$ ribonuclease A (all from Sigma) for $30 \mathrm{~min}$ at RT, and acquired in an FACSCanto cytometer (BD Biosciences). Data were analyzed with the FCS Express 4 Flow software adjusting cell cycle profiles with the predefined autofit $+\mathrm{S}$ order $=1$ model and represented as the percentage of cells in each phase relative to the total cell number \pm SEM (mean of three experiments).

\section{Gap-filling assays}

To perform this assay, $6.5 \times 10^{4}$ cells were seeded in each well of a $\mu$-dish, $35-\mathrm{mm}$, low, culture insert plate (Ibidi). In these plates, a silicone dam of $500 \mu \mathrm{m}$ separates the plating space in two identical wells, in which cells expressing the same or different AQP8 variants were cultured until confluence was reached. Cells were then incubated at either $37^{\circ} \mathrm{C}$ or $42^{\circ} \mathrm{C}$ in $2 \% \mathrm{FBS}$ for $3 \mathrm{~h}$ as described. After that period, dams were removed, leaving a defined cell-free gap, and the medium was increased to 5\% FBS to stimulate gap filling. In some experiments, $2 \mathrm{n} M$ TMR ligand was added to identify transfectants expressing the protein of interest. Time-lapse $10 \times$ photographs of gap closure were taken every $5 \mathrm{~min}$ for up to $24 \mathrm{~h}$ using a Zeiss Axiovert S100 TV2 microscope (Zeiss) equipped with a Hamamatsu OrcaII-ER camera and analyzed using ImageJ or Oko-vision (Okolab) software. Five independent experiments were performed. Data are represented as the average percentage of gap closure plotted against time \pm SEM.

\section{Analysis of p38 activation and oxidative modifications of HaloAQP8}

To follow p38 phosphorylation, subconfluent HeLa cultures (80-90\%) stably expressing AQP8 wt or AQP8 C53S recombinant proteins were cultured in $2 \% \mathrm{FBS}$ for $3 \mathrm{~h}$ at $37^{\circ} \mathrm{C}$ or $42^{\circ} \mathrm{C}$ with or without $2 \mathrm{mM}$ NAC. Cells were then washed once with ice-cold PBS and scraped in a buffer containing $62.5 \mathrm{~m} M$ Tris, $1 \%$ sodium dodecyl sulfate (SDS), $10 \%$ glycerol, and $5 \mathrm{~m} M$ DTT supplemented with freshly added protease inhibitors (Roche), $10 \mathrm{~m} M$ N-ethylmaleimide (NEM), $0.4 \mathrm{~m} M \mathrm{Na}_{3} \mathrm{VO}_{4}$, and $10 \mathrm{~m} M \mathrm{NaF}$ (all from Sigma). Cell lysates were sonicated twice at maximum intensity for $10 \mathrm{~min}$ and aliquots resolved by standard SDS-PAGE electrophoresis, followed by Western blotting. The experiments were performed eight times (p38 phosphorylation) or at least twice (NAC inhibition of $\mathrm{p} 38$ phosphorylation), giving similar results.

To analyze the changes in mobility of the HaloAQP8 recombinant protein, subconfluent HeLa cultures (80-90\%) stably expressing AQP8 wt were washed once with ice-cold PBS and scraped in RIPA buffer (0.1\% SDS, $1 \%$ NP40, $150 \mathrm{~m} M \mathrm{NaCl}, 50 \mathrm{~m} M$ Tris, $\mathrm{pH}$ 7.4) supplemented with freshly added protease inhibitors, $10 \mathrm{mM}$ NEM, $0.4 \mathrm{~m} M$ $\mathrm{Na}_{3} \mathrm{VO}_{4}$, and $10 \mathrm{~m} M \mathrm{NaF}$. Whole HeLa cell lysates were centrifuged at $15,000 \mathrm{rpm}, 15 \mathrm{~min}$ at $4^{\circ} \mathrm{C}$, and used in standard reducing and nonreducing electrophoresis, followed by Western blotting. The experiments were repeated at least thrice and gave similar results.

To investigate the sulfenylation of HaloAQP8 recombinant protein, subconfluent HeLa cultures (80-90\%) transiently expressing myc-tagged $\mathrm{AQP} 8$ wt or $\mathrm{C} 53 \mathrm{~S}$ cells were either treated with the indicated concentrations of $\mathrm{H}_{2} \mathrm{O}_{2}$ or subjected to heat stress, washed with ice-cold PBS, and scraped in
RIPA buffer supplemented with fresly added protease inhibitors, $0.4 \mathrm{~m} M \mathrm{Na}_{3} \mathrm{VO}_{4}, 10 \mathrm{~m} M \mathrm{NaF}$, and $250 \mathrm{~m} M$ of the sulfenylation-detecting probe, DCP-Bio1 (EMD Millipore). Whole HeLa cell lysates were centrifuged at $15,000 \mathrm{rpm}$, $15 \mathrm{~min}$ at $4^{\circ} \mathrm{C}$, and postnuclear supernatant was quantified. One milligram of total protein was then used for immunoprecipitation with homemade cross-linked anti-myc sepharose beads and eluted by boiling in SDS-containing sample buffer.

\section{Antibodies and Western blotting}

Primary antibodies, rabbit $\alpha$-p38 and rabbit $\alpha$-phospho-p38 (Thr180/Tyr181), were purchased from Cell Signaling Technology. Anti-Halo antibody was purchased from Promega. Rabbit $\alpha$-HIF1a was from Cayman Chemical, while mouse anti-tubulin was from Sigma. Secondary antibodies, $\alpha$-rabbit Alexa Fluor 488 or Alexa Fluor 647, were purchased from Invitrogen.

Images were acquired using a Typhoon FLA-9000 (GE HealthCare), processed with ImageJ, and densitometrically quantified when indicated by ImageQuant TL software (GE HealthCare) \pm SEM.

\section{Water transport in yeast}

Saccharomyces cerevisiae wild-type strain BY4741 was transformed with pYeDP60u mock vector or pYeDP60u containing indicated AQP8 variant encoding genes. Transformants were selected on synthetic medium (2\% agar, $2 \%$ glucose, $50 \mathrm{mM}$ succinic acid/Tris base, $\mathrm{pH} 5.5$, and $0.7 \%$ YNB (yeast nitrogen base) without amino acids (Difco) supplemented according to the auxotrophic requirements with histidine, methionine, and leucine. Transformants were grown in $4 \mathrm{ml}$ of above described synthetic medium for $12 \mathrm{~h}$ at $30^{\circ} \mathrm{C}$ and then transferred to $25 \mathrm{ml}$ of synthetic medium ( $2 \%$ glucose replaced by $2 \%$ galactose) for $36 \mathrm{~h}$ at $30^{\circ} \mathrm{C}$. After centrifugation, cells were resuspended in $3 \mathrm{ml}$ of $50 \mathrm{mM} \mathrm{KH}_{2} \mathrm{PO}_{4}$ (pH 7.2) plus $6 \mu \mathrm{l}$ of 2-mercaptoethanol, and incubated for $15 \mathrm{~min}$ at $30^{\circ} \mathrm{C}$. Six milliliters of spheroplasting

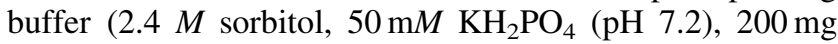
bovine serum albumin, and $10 \mathrm{mg}$ of Zymolase 20T (Amsbio) was added to the cell suspension. The cells were incubated for $60 \mathrm{~min}$ at $30^{\circ} \mathrm{C}$. Following centrifugation, spheroplasts were washed once and finally resuspended in $10 \mathrm{~m} M$ Tris/MES, $\mathrm{pH}$ $8.0,5 \mathrm{~m} M \mathrm{CaCl}_{2}, 50 \mathrm{mM} \mathrm{NaCl}$, and $1.8 M$ sorbitol at an $\mathrm{A}_{600}$ of 1.5. Kinetics of spheroplast swelling was measured essentially as described previously (29). Cell osmotic water permeability was measured after exposing spheroplasts to hyposmotic conditions (transfer from 1.8 to $1.2 \mathrm{~m} M$ sorbitol buffer). Volume changes were recorded via light scattering at an angle of $90^{\circ}$ and $450 \mathrm{~nm}$ using a fast kinetics instrument (SFM-3000; BioLogic) at $25^{\circ} \mathrm{C}$ with a dead time of $1.5 \mathrm{~ms}$. The time course of swelling was measured for 3-8 s at the acquisition rate of one measurement/0.0005 s. All data presented are averages of 15 to 30 trace recordings. The rate constant of the decrease of scattered light intensity is proportional to the water permeability coefficient $(9,26)$. Rate constants were calculated by fitting the curves using nonlinear regression as described by Liu et al. (34). One-exponential functions were used for control spheroplasts and twoexponential functions were used for AQP8 and its variants expressing spheroplasts. At least two independent experiments were performed, which gave consistent results. 


\section{Growth assay with hydrogen peroxide}

For $\mathrm{H}_{2} \mathrm{O}_{2}$ growth toxicity assays, $S$. cerevisiae wild-type strain BY4741 was transformed with pYeDP60u mock vector or pYeDP60u carrying indicated AQP8 variant encoding genes. Transformants were selected on synthetic medium as described above. The toxicity growth assay was performed as described by Bienert et al. (7). Transformants were spotted on synthetic medium supplemented with different concentrations of $\mathrm{H}_{2} \mathrm{O}_{2}$ and galactose instead of glucose as a carbon source necessary for the induction of the galactose-inducible promoter. After 5-9 days of incubation at $30^{\circ} \mathrm{C}$, differences in growth and survival in the different assays were recorded. All yeast growth assays were performed in three independent experiments with consistent results.

\section{Total internal reflection microscopy}

In TIRF microscopy, a thin layer close to the coverslip/ sample interface is illuminated via a collimated beam impinging on the coverslip at an angle of incidence larger than the critical angle. The beam is totally reflected and only the evanescent field with a penetration depth of approximately $90 \mathrm{~nm}$ excites the sample in the case of a glass-oil interface and an excitation wavelength of $534 \mathrm{~nm}$. This method is ideal for imaging thin layers, such as the plasma membrane of a cell, with minimum background fluorescence, and hence allows us to study AQP8 movements from the plasma membrane. Briefly, $3 \times 10^{5}$ HeLa cells stably expressing HaloAQP8 wt were seeded $48 \mathrm{~h}$ before the experiment and labeled with $2 \mathrm{n} M$ HaloTag TMR Direct Ligand for $24 \mathrm{~h}$. TIRF images were collected every minute for $2 \mathrm{~h}$ by excitation with a $530 \mathrm{~nm}$ laser on a Widefield Leica SR GSD 3D TIRF (Leica) equipped with an incubator set at $42^{\circ} \mathrm{C}$ with controlled $\mathrm{CO}_{2}$ pressure, using a $63 \times$ oil immersion lens. Two independent experiments were performed, leading to identical results.

\section{FACS analyses}

To quantify AQP8 membrane expression by FACS, HeLa cells were transiently transfected with a plasmid driving the expression of HaloAQP8 myc-out. Forty-eight hours later, cells were incubated for $3 \mathrm{~h}$ at $37^{\circ} \mathrm{C}$ or $42^{\circ} \mathrm{C}$, detached from plates on ice, and counted; $4 \times 10^{5}$ cells were stained with standard 9E10 anti-myc antibodies, followed by detection with $\alpha$-mouse Alexa Fluor 488. Nontrasfected cells were used as negative control, while binding of the TMR Halo ligand was used as transfection control. FACS analyses ( $\geq 3$ experiments) were performed in an FACSCanto cytometer and surface expression represented using the FCS Express 4 Flow software.

\section{Statistical analyses}

Statistics were calculated either by using the two-sample $t$-test for independent samples or the one-way ANOVA method for multiple samples. When using the latter, Tukey's HSD post hoc test was also applied to find out which groups were significantly different from others. In all cases, statistical significance

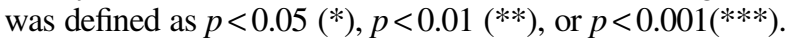

\section{Acknowledgments}

The authors thank Drs. V. Belousov and R. Bernardi for providing reagents, C. Fagioli for technical help, and mem- bers of the Rubartelli, Sitia, and van Anken laboratories at the Division of Genetics and Cell Biology for stimulating discussions and helpful suggestions. Part of this work was carried out in the Advanced Light and Electron Microscopy BioImaging Center (ALEMBIC) of San Raffaele Scientific Institute and Vita-Salute University. This work was supported by grants from Associazione Italiana Ricerca Cancro (AIRC; IG and $5 \times 1000$ programs), Ministero della Salute RF 2011-2012 PE-2011-02352286, Regione Lombardia (ASTIL), and Telethon (GGP11077). G.P.B was supported by an Emmy Noether grant 1668/1-1 from the Deutsche Forschungsgemeinschaft.

\section{Author Contributions}

I.M.F. and S.B. performed and analyzed the experiments. U.L. and C.B. performed and analyzed the water transport experiments. G.P.B. measured and analyzed water permeability and $\mathrm{H}_{2} \mathrm{O}_{2}$ sensitivity in yeast. A.R. suggested the DPI experiments and helped in interpreting the results. M.B. performed part of the experiment in Figure 1A. R.S. conceived and supervised the study. I.M.F., S.B., A.R., and R.S. wrote the manuscript.

\section{Author Disclosure Statement}

The authors declare that they have no conflicts of interest.

\section{References}

1. Agre P. The aquaporin water channels. Proc Am Thorac Soc 3: 5-13, 2006.

2. Arnold K, Bordoli L, Kopp J, and Schwede T. The SWISSMODEL workspace: a web-based environment for protein structure homology modelling. Bioinformatics 22: 195201, 2006.

3. Axelrod D, Thompson NL, and Burghardt TP. Total internal inflection fluorescent microscopy. J Microsc 129: 19-28, 1983.

4. Bedard K and Krause KH. The NOX family of ROSgenerating NADPH oxidases: physiology and pathophysiology. Physiol Rev 87: 245-313, 2007.

5. Belousov VV, Fradkov AF, Lukyanov KA, Staroverov DB, Shakhbazov KS, Terskikh AV, and Lukyanov S. Genetically encoded fluorescent indicator for intracellular hydrogen peroxide. Nat Methods 3: 281-286, 2006.

6. Bertolotti M, Bestetti S, Garcia-Manteiga JM, MedranoFernandez I, Dal Mas A, Malosio ML, and Sitia R. ETyrosine kinase signal modulation: a matter of $\mathrm{H} 2 \mathrm{O} 2$ membrane permeability? Antioxid Redox Signal 19: 1447-1451, 2013.

7. Bienert GP, Moller AL, Kristiansen KA, Schulz A, Moller IM, Schjoerring JK, and Jahn TP. Specific aquaporins facilitate the diffusion of hydrogen peroxide across membranes. J Biol Chem 282: 1183-1192, 2007.

8. Boussif O, Lezoualc'h F, Zanta MA, Mergny MD, Scherman D, Demeneix B, and Behr JP. A versatile vector for gene and oligonucleotide transfer into cells in culture and in vivo: polyethylenimine. Proc Natl Acad Sci U S A 92: 7297-7301, 1995.

9. Calamita G, Ferri D, Gena P, Liquori GE, Cavalier A, Thomas D, and Svelto M. The inner mitochondrial membrane has aquaporin- 8 water channels and is highly permeable to water. J Biol Chem 280: 17149-17153, 2005.

10. Campisi J and d'Adda di Fagagna F. Cellular senescence: when bad things happen to good cells. Nat Rev Mol Cell Biol 8: 729-740, 2007. 
11. Cenci S, Mezghrani A, Cascio P, Bianchi G, Cerruti F, Fra A, Lelouard H, Masciarelli S, Mattioli L, Oliva L, Orsi A, Pasqualetto E, Pierre P, Ruffato E, Tagliavacca L, and Sitia R. Progressively impaired proteasomal capacity during terminal plasma cell differentiation. EMBO J 25: 11041113, 2006

12. Chiarugi P, Pani G, Giannoni E, Taddei L, Colavitti R, Raugei G, Symons M, Borrello S, Galeotti T, and Ramponi G. Reactive oxygen species as essential mediators of cell adhesion: the oxidative inhibition of a FAK tyrosine phosphatase is required for cell adhesion. J Cell Biol 161: 933-944, 2003.

13. Clark CB, Rane MJ, El Mehdi D, Miller CJ, Sachleben LR, Jr., and Gozal E. Role of oxidative stress in geldanamycininduced cytotoxicity and disruption of Hsp90 signaling complex. Free Radic Biol Med 47: 1440-1449, 2009.

14. DeNicola GM, Karreth FA, Humpton TJ, Gopinathan A, Wei C, Frese K, Mangal D, Yu KH, Yeo CJ, Calhoun ES, Scrimieri F, Winter JM, Hruban RH, Iacobuzio-Donahue C, Kern SE, Blair IA, and Tuveson DA. Oncogene-induced Nrf2 transcription promotes ROS detoxification and tumorigenesis. Nature 475: 106-109, 2011.

15. DeYulia GJ, Jr., Carcamo JM, Borquez-Ojeda O, Shelton $\mathrm{CC}$, and Golde DW. Hydrogen peroxide generated extracellularly by receptor-ligand interaction facilitates cell signaling. Proc Natl Acad Sci U S A 102: 5044-5049, 2005.

16. Fulda S, Gorman AM, Hori O, and Samali A. Cellular stress responses: cell survival and cell death. Int J Cell Biol 2010: 214074, 2010.

17. Geiszt $\mathrm{M}$ and Leto TL. The Nox family of NAD(P)H oxidases: host defense and beyond. J Biol Chem 279: 5171551718, 2004.

18. Hara-Chikuma M, Satooka H, Watanabe S, Honda T, Miyachi Y, Watanabe T, and Verkman AS. Aquaporin-3mediated hydrogen peroxide transport is required for NFkappaB signalling in keratinocytes and development of psoriasis. Nat Commun 6: 7454, 2015.

19. Harris IS, Treloar AE, Inoue S, Sasaki M, Gorrini C, Lee KC, Yung KY, Brenner D, Knobbe-Thomsen CB, Cox MA, Elia A, Berger T, Cescon DW, Adeoye A, Brustle A, Molyneux SD, Mason JM, Li WY, Yamamoto K, Wakeham A, Berman HK, Khokha R, Done SJ, Kavanagh TJ, Lam CW, and Mak TW. Glutathione and thioredoxin antioxidant pathways synergize to drive cancer initiation and progression. Cancer Cell 27: 211-222, 2015.

20. Hielscher A and Gerecht S. Hypoxia and free radicals: role in tumor progression and the use of engineering-based platforms to address these relationships. Free Radic Biol Med 79: 281-291, 2015.

21. Holmstrom KM and Finkel T. Cellular mechanisms and physiological consequences of redox-dependent signalling. Nat Rev Mol Cell Biol 15: 411-421, 2014.

22. Ishibashi K, Kuwahara M, Kageyama Y, Tohsaka A, Marumo F, and Sasaki S. Cloning and functional expression of a second new aquaporin abundantly expressed in testis. Biochem Biophys Res Commun 237: 714-718, 1997.

23. Jiang F, Zhang Y, and Dusting GJ. NADPH oxidase-mediated redox signaling: roles in cellular stress response, stress tolerance, and tissue repair. Pharmacol Rev 63: 218-242, 2011.

24. Kasanuma Y, Watanabe C, Kim CY, Yin K, and Satoh H. Effects of mild chronic heat exposure on the concentrations of thiobarbituric acid reactive substances, glutathione, and selenium, and glutathione peroxidase activity in the mouse liver. Tohoku J Exp Med 185: 79-87, 1998.
25. Kim YX and Steudle E. Gating of aquaporins by light and reactive oxygen species in leaf parenchyma cells of the midrib of Zea mays. J Exp Bot 60: 547-556, 2009.

26. Kozono D, Ding X, Iwasaki I, Meng X, Kamagata Y, Agre P, and Kitagawa Y. Functional expression and characterization of an archaeal aquaporin. AqpM from methanothermobacter marburgensis. J Biol Chem 278: 10649-10656, 2003.

27. Kultz D. Molecular and evolutionary basis of the cellular stress response. Annu Rev Physiol 67: 225-257, 2005.

28. Laforenza U, Cova E, Gastaldi G, Tritto S, Grazioli M, LaRusso NF, Splinter PL, D'Adamo P, Tosco M, and Ventura U. Aquaporin-8 is involved in water transport in isolated superficial colonocytes from rat proximal colon. J Nutr 135: 2329-2336, 2005.

29. Laize V, Gobin R, Rousselet G, Badier C, Hohmann S, Ripoche P, and Tacnet F. Molecular and functional study of AQY1 from Saccharomyces cerevisiae: role of the C-terminal domain. Biochem Biophys Res Commun 257: 139-144, 1999.

30. LaMacchia JC and Roth MB. Aquaporins-2 and -4 regulate glycogen metabolism and survival during hyposmoticanoxic stress in Caenorhabditis elegans. Am J Physiol Cell Physiol 309: C92-C6, 2015.

31. Li Y and Trush MA. Diphenyleneiodonium, an NAD(P)H oxidase inhibitor, also potently inhibits mitochondrial reactive oxygen species production. Biochem Biophys Res Commun 253: 295-299, 1998.

32. Lim EJ, Heo J, and Kim YH. Tunicamycin promotes apoptosis in leukemia cells through ROS generation and downregulation of survivin expression. Apoptosis 20: 1087-1098, 2015.

33. Liou GY and Storz P. Reactive oxygen species in cancer. Free Radic Res 44: 479-496, 2010.

34. Liu K, Nagase H, Huang CG, Calamita G, and Agre P. Purification and functional characterization of aquaporin-8. Biol Cell 98: 153-161, 2006.

35. Lo Conte M and Carroll KS. The redox biochemistry of protein sulfenylation and sulfinylation. J Biol Chem 288: 26480-26488, 2013.

36. Marinho HS, Real C, Cyrne L, Soares H, and Antunes F. Hydrogen peroxide sensing, signaling and regulation of transcription factors. Redox Biol 2: 535-562, 2014.

37. Marino SM and Gladyshev VN. Proteomics: mapping reactive cysteines. Nat Chem Biol 7: 72-73, 2011.

38. Meng TC, Fukada T, and Tonks NK. Reversible oxidation and inactivation of protein tyrosine phosphatases in vivo. Mol Cell 9: 387-399, 2002.

39. Miller EW, Dickinson BC, and Chang CJ. Aquaporin-3 mediates hydrogen peroxide uptake to regulate downstream intracellular signaling. Proc Natl Acad Sci U S A 107: 15681-15686, 2010.

40. Mossuto MF, Sannino S, Mazza D, Fagioli C, Vitale M, Yoboue ED, Sitia R, and Anelli T. A dynamic study of protein secretion and aggregation in the secretory pathway. PLoS One 9: e108496, 2014.

41. Nelson KJ, Klomsiri C, Codreanu SG, Soito L, Liebler DC, Rogers LC, Daniel LW, and Poole LB. Use of dimedonebased chemical probes for sulfenic acid detection methods to visualize and identify labeled proteins. Methods Enzymol 473: 95-115, 2010.

42. Nerini-Molteni S, Ferrarini M, Cozza S, Caligaris-Cappio F, and Sitia R. Redox homeostasis modulates the sensitivity of myeloma cells to bortezomib. Br J Haematol 141: 494503, 2008. 
43. Nielsen S, Chou CL, Marples D, Christensen EI, Kishore BK, and Knepper MA. Vasopressin increases water permeability of kidney collecting duct by inducing translocation of aquaporin-CD water channels to plasma membrane. Proc Natl Acad Sci U S A 92: 1013-1017, 1995.

44. Ovalle S, Gutierrez-Lopez MD, Olmo N, Turnay J, Lizarbe MA, Majano P, Molina-Jimenez F, Lopez-Cabrera M, Yanez-Mo M, Sanchez-Madrid F, and Cabanas C. The tetraspanin CD9 inhibits the proliferation and tumorigenicity of human colon carcinoma cells. Int J Cancer 121: 2140-2152, 2007.

45. Pani G, Galeotti T, and Chiarugi P. Metastasis: cancer cell's escape from oxidative stress. Cancer Metastasis Rev 29: 351-378, 2010.

46. Paulsen CE, Truong TH, Garcia FJ, Homann A, Gupta V, Leonard SE, and Carroll KS. Peroxide-dependent sulfenylation of the EGFR catalytic site enhances kinase activity. Nat Chem Biol 8: 57-64, 2012.

47. Potokar M, Stenovec M, Jorgacevski J, Holen T, Kreft M, Ottersen OP, and Zorec R. Regulation of AQP4 surface expression via vesicle mobility in astrocytes. Glia 61: 917-928, 2013.

48. Preston GM, Carroll TP, Guggino WB, and Agre P. Appearance of water channels in Xenopus oocytes expressing red cell CHIP28 protein. Science 256: 385-387, 1992.

49. Putker M, Vos HR, van Dorenmalen K, de Ruiter H, Duran AG, Snel B, Burgering BM, Vermeulen M, and Dansen TB. Evolutionary acquisition of cysteines determines FOXO paralog-specific redox signaling. Antioxid Redox Signal 22: 15-28, 2015.

50. Reth M. Hydrogen peroxide as second messenger in lymphocyte activation. Nat Immunol 3: 1129-1134, 2002.

51. Santos CX, Tanaka LY, Wosniak J, and Laurindo FR. Mechanisms and implications of reactive oxygen species generation during the unfolded protein response: roles of endoplasmic reticulum oxidoreductases, mitochondrial electron transport, and NADPH oxidase. Antioxid Redox Signal 11: 2409-2427, 2009.

52. Shaughnessy DT, McAllister K, Worth L, Haugen AC, Meyer JN, Domann FE, Van Houten B, Mostoslavsky R, Bultman SJ, Baccarelli AA, Begley TJ, Sobol RW, Hirschey MD, Ideker T, Santos JH, Copeland WC, Tice RR, Balshaw DM, and Tyson FL. Mitochondria, energetics, epigenetics, and cellular responses to stress. Environ Health Perspect 122: 1271-1278, 2014.

53. Shutt DC, O’Dorisio MS, Aykin-Burns N, and Spitz DR. 2-deoxy-D-glucose induces oxidative stress and cell killing in human neuroblastoma cells. Cancer Biol Ther 9: 853861, 2010.

54. Tiligada E. Chemotherapy: induction of stress responses. Endocr Relat Cancer 13 Suppl 1: S115-S24, 2006.

55. Tobiume K, Matsuzawa A, Takahashi T, Nishitoh H, Morita K, Takeda K, Minowa O, Miyazono K, Noda T, and Ichijo $\mathrm{H}$. ASK1 is required for sustained activations of $\mathrm{JNK} / \mathrm{p} 38$ MAP kinases and apoptosis. EMBO Rep 2: 222-228, 2001.

56. Vermes I, Haanen C, Steffens-Nakken H, and Reutelingsperger C. A novel assay for apoptosis. Flow cyto- metric detection of phosphatidylserine expression on early apoptotic cells using fluorescein labelled Annexin V. J Immunol Methods 184: 39-51, 1995.

57. Vieceli Dalla Sega F, Zambonin L, Fiorentini D, Rizzo B, Caliceti C, Landi L, Hrelia S, and Prata C. Specific aquaporins facilitate Nox-produced hydrogen peroxide transport through plasma membrane in leukaemia cells. Biochim Biophys Acta 1843: 806-814, 2014.

58. Woo HA, Yim SH, Shin DH, Kang D, Yu DY, and Rhee SG. Inactivation of peroxiredoxin I by phosphorylation allows localized $\mathrm{H}(2) \mathrm{O}(2)$ accumulation for cell signaling. Cell 140: 517-528, 2010.

59. Ye Q and Steudle E. Oxidative gating of water channels (aquaporins) in corn roots. Plant Cell Environ 29: 459-470, 2006.

60. Zhou S, Ye W, Shao Q, Zhang M, and Liang J. Nrf2 is a potential therapeutic target in radioresistance in human cancer. Crit Rev Oncol Hematol 88: 706-715, 2013.

Address correspondence to:

Dr. Roberto Sitia

Protein Transport and Secretion Unit Division of Genetics and Cell Biology IRCCS Ospedale San Raffaele/Università Vita-Salute San Raffaele Milan 20132 Italy

E-mail: sitia.roberto@hsr.it

Date of first submission to ARS Central, January 13, 2016; date of final revised submission, February 29, 2016; date of acceptance, March 8, 2016.

$$
\begin{aligned}
& \text { Abbreviations Used } \\
\text { 2-DG } & =2 \text {-deoxyglucose } \\
\text { AQP } & =\text { aquaporin protein } \\
\text { AQP8 } & =\text { aquaporin- } 8 \\
\text { DPI } & =\text { diphenyleneiodonium } \\
\text { DTT } & =\text { dithiothreitol } \\
\text { MAPK } & =\text { mitogen-activated kinase } \\
\text { NAC } & =\text { N-acetyl-cysteine } \\
\text { NEM } & =\text { N-ethylmaleimide } \\
\text { NOX } & =\text { NADPH oxidase } \\
\text { PEI } & =\text { polyethylenimine } \\
\text { PI } & =\text { propidium iodide } \\
\text { PK } & =\text { protein kinase } \\
\text { Prx } 1 & =\text { peroxiredoxin- } 1 \\
\text { ROS } & =\text { reactive oxygen species } \\
\text { SDS } & =\text { sodium dodecyl sulfate } \\
\text { TIRF } & =\text { total internal reflection } \\
\text { TKR } & =\text { tyrosine kinase receptor } \\
\mathrm{wt} & =\text { wild type }
\end{aligned}
$$

